\title{
Dual Control of Neurogenesis by PC3 through Cell Cycle Inhibition and Induction of Math1
}

\author{
Daniela Canzoniere, ${ }^{1 *}$ Stefano Farioli-Vecchioli, ${ }^{1 *}$ Filippo Conti, ${ }^{1}$ Maria Teresa Ciotti, ${ }^{1}$ Ada Maria Tata, ${ }^{3}$ \\ Gabriella Augusti-Tocco, ${ }^{3}$ Elisabetta Mattei, ${ }^{2}$ Madepalli K. Lakshmana, ${ }^{1}$ Valery Krizhanovsky, ${ }^{4}$ Steven A. Reeves, ${ }^{5}$ \\ Roberto Giovannoni, ${ }^{6}$ Francesca Castano, ${ }^{6}$ Antonio Servadio, ${ }^{6}$ Nissim Ben-Arie, ${ }^{4}$ and Felice Tirone ${ }^{1}$ \\ ${ }^{1}$ Istituto Neurobiologia e Medicina Molecolare and ${ }^{2}$ Istituto Biologia e Patologia Molecolare, Consiglio Nazionale delle Ricerche, 00156 Rome, Italy, \\ ${ }^{3}$ Dipartimento Biologia Cellulare e dello Sviluppo, Università Sapienza, 00185 Rome, Italy, ${ }^{4}$ Department of Cell and Animal Biology, The Hebrew University \\ of Jerusalem, Jerusalem 91904, Israel, ${ }^{5}$ Central Nervous System Signaling Laboratory, Center for Aging, Genetics, and Neurodegeneration, Massachusetts \\ General Hospital, Harvard Medical School, Charlestown, Massachusetts 02129, and ${ }^{6}$ Telethon Institute of Genetics and Medicine, 00161 Naples, Italy
}

Growing evidence indicates that cell cycle arrest and neurogenesis are highly coordinated and interactive processes, governed by cell cycle genes and neural transcription factors. The gene PC3 (Tis21/BTG2) is expressed in the neuroblast throughout the neural tube and inhibits cell cycle progression at the $\mathrm{G}_{1}$ checkpoint by repressing cyclin $D 1$ transcription. We generated inducible mouse models in which the expression of $P C 3$ was upregulated in neuronal precursors of the neural tube and of the cerebellum. These mice exhibited a marked increase in the production of postmitotic neurons and impairment of cerebellar development. Cerebellar granule precursors of PC3 transgenic mice displayed inhibition of cyclin D1 expression and a strong increase in the expression of Math1, a transcription factor required for their differentiation. Furthermore, $P C 3$, encoded by a recombinant adenovirus, also induced Math1 in postmitotic granule cells in vitro and stimulated the Math 1 promoter activity. In contrast, $P C 3$ expression was unaffected in the cerebellar primordium of Math1 null mice, suggesting that PC3 acts upstream to Math1. As a whole, our data suggest that cell cycle exit of cerebellar granule cell precursors and the onset of cerebellar neurogenesis are coordinated by PC3 through transcriptional control of cyclin D1 and Math1, respectively.

Key words: cyclin D1; Math1; NeuroD1; nestin; neuroepithelia; tet-on/off

\section{Introduction}

Neurogenesis occurs through the production of postmitotic neurons from neuroepithelial stem cells localized in the ventricular zone (VZ) of the neural tube by progressive steps of cell cycle exit, differentiation, and migration. Neuronal progenitors acquire the correct positional identity under the influence of homeotic genes and patterning signals and are further specified by basic helixloop-helix transcription factors, like Mash1, Neurogenins, and Math1 (Johnson et al., 1990; Akazawa et al., 1995; Ben-Arie et al., 1996; Ma et al., 1996).

Math1 is expressed in cerebellar granule cell progenitors (GCPs) and is required for their differentiation into granule cells

\footnotetext{
Received Aug. 19, 2003; revised Jan. 19, 2004; accepted Jan. 21, 2004.

This work was supported by Donazione Bianchi (F.T.), Progetto Finalizzato Consiglio Nazionale delle Ricerche "Terapia preclinica molecolare in oncologia" (F.T.), European Union Grant QLG3-(T-2000-00072 (F.T. and N.B.A.), and by Telethon (A.S.). We thank Hermann Rohrer and Maurizia Caruso for critical reading and advice, (ecilia Tiveron and Laura Tatangelo for help in the creation of the nACT37 mouse lineage, and Marco Crescenzi and Milena Grossi for their gift of adenoviruses carrying p21 and p27.

*D.C. and S.F.-V. contributed equally to this work.

Correspondence should be addressed to Felice Tirone, Istituto di Neurobiologia e Medicina Molecolare, Consiglio Nazionale delle Ricerche, Viale Marx 15, 00156 Rome, Italy. E-mail: tirone@in.rm.cnr.it.

R. Giovannoni's present address: Dipartimento Medicina Sperimentale Ambientale e Biotecnologie Mediche, Università Milano-Bicocca, 20126 Milano, Italy.

A. Servadio's present address: Center for Neurosciences, University of Insubria, 21052 Busto Arsizio, Italy. D0I:10.1523/JNEUROSCI.3860-03.2004

Copyright $\odot 2004$ Society for Neuroscience $\quad$ 0270-6474/04/243355-15\$15.00/0
}

(Ben-Arie et al., 1997). GCPs are derived from the rhombic lip, a germinative epithelium positioned at the roofplate of the fourth ventricle, and are specified as early as embryonic day 10.5 (E10.5) in mice (Alder et al., 1996). These progenitors migrate from the rhombic lip over the surface of the cerebellar anlage to form the external granule layer (EGL) of the cerebellar primordia (Wingate, 2001). GCPs in the EGL express Math1 and proliferate until the second week of postnatal life. Mature granule cells arise by exit from the cell cycle and inward migration to form the cerebellar internal granule layer (IGL), below the Purkinje cell soma (Fujita et al., 1966; Rakic, 1971). In the absence of Math1, rhombic lip CGPs are generated, but the EGL is never formed (BenArie et al., 1997).

Remarkably, the ectopic expression of Math1 and other proneural genes not only converts undifferentiated precursors into neurons but is also linked to a negative control of the cell cycle (Farah et al., 2000). Such a dual function answers the requirement for coordination between cell cycle exit and the specification of neuronal fate, effective during the last mitotic cycle (McConnell and Kaznowski, 1991; Eagleson et al., 1997; Belliveau and Cepko, 1999; Ohnuma et al., 2001).

The antiproliferative gene PC3 was isolated as an immediate early gene induced during NGF-dependent differentiation of the PC12 pheochromocytoma cell line (Bradbury et al., 1991) (for review, see Matsuda et al., 2001; Tirone, 2001). This cell line is a 
tumor counterpart of chromaffin cells, which are a neural crest derivative (Greene, 1978). PC3 mRNA is expressed in the neuroblast of the ventricular zone of the neural tube during the last proliferative cycle before differentiation into a postmitotic neuron and is therefore a marker for the birth of the neuron (Bradbury et al., 1991; Iacopetti et al., 1994, 1999). Moreover, the ability of PC3 to induce cell cycle arrest in $G_{1}$ by inhibiting the transcription of cyclin D1, as was observed in fibroblasts (Guardavaccaro et al., 2000), and to potentiate the NGFmediated neuronal differentiation of pheochromocytoma cells (Corrente et al., 2002; el-Ghissassi et al., 2002) suggested that PC3 could act as a switch from proliferative to neuron-generating cell fate. To test this hypothesis, we produced two transgenic mouse models conditionally overexpressing PC3 in neuroepithelia. In both transgenic models, we observed inhibition of proliferation accompanied by a striking increase of the differentiation of neuronal precursors in the embryonic CNS and postnatal cerebellum, with a reduced cerebellar size evident at birth, and transcriptional induction of Math1 in cerebellar granule cells. Together, our data imply that PC3 is a key gene in the control of the shift from proliferation to differentiation in the CNS.

\section{Materials and Methods}

Transgene constructs. The TRE-PC3 construct (pUHD10-3-PC3) was produced by subcloning the $P C 3$ open reading frame (ORF) (Bradbury et al., 1991) into the EcoRI site of pUHD10-3 (Gossen and Bujard, 1992). The $1.45 \mathrm{~kb}$ transgene (XhoI-HindIII of pUHD10-3-PC3) included the PC3 ORF under the control of seven copies of the tetracycline responsive element (TRE), followed by the minimal cytomegalovirus (CMV) promoter (XhoI-EcoRI fragment) and the simian virus 40 (SV40) poly(A) site downstream of the PC3 ORF (EcoRI-HindIII region) (Fig. $1 A$ ).

To construct the $\beta$ ACT-tTA (tetracycline-regulated transactivator) transgene, the human $\beta$-actin promoter, the $5^{\prime}$ untranslated region (UTR) and the IVS1 splice acceptor of the human $\beta$-actin gene (corresponding to an EcoRI-SalI fragment of $4.8 \mathrm{~kb}$ ), followed by the tTA coding sequence (XbaI-BamHI fragment excised from pUHD15-1) (Gossen and Bujard, 1992) and the 3' UTR of the human $\beta$-actin gene, were assembled in a pZeo SV2 $(+)$ backbone (Invitrogen, San Diego, CA). This latter was modified by deleting the localization signal (between the SnaBI and NsiI sites) to obtain higher mRNA stability and perinuclear localization of the tTA transcript (Qin and Gunning, 1997). The whole $6 \mathrm{~kb}$ transgene was excised by EcoRI-KpnI (Fig. $1 \mathrm{~B}$ ).

The assembly of the nestin promoter-rtTA transgene has been described previously (Mitsuhashi et al., 2001).

The tTA protein (tetR/VP16) produced by the $\beta$ ACT-tTA construct binds and activates TRE-PC3 in the absence of tetracycline. Conversely, the rtTA protein (r-tetR/VP16) produced by the nestin-rtTA construct (Mitsuhashi et al., 2001), modified in four amino acids of tetR (Kistner et al., 1996), binds and activates TRE-PC3 in the presence of tetracycline (2 $\mathrm{mg} / \mathrm{ml}$ in the drinking water) (Fig. $1 A, B$ ).

Transgenic animals, genotyping, and Southern blot analysis. Transgenic constructs were obtained by isolating either the $6 \mathrm{~kb} E c o R I-K p n \mathrm{I}$ fragment of $\beta$ ACT-tTA or the $1.45 \mathrm{~kb}$ XhoI-HindIII fragment of TRE-PC3. Purified DNA ( $5 \mathrm{ng} / \mathrm{ml}$ ) was injected into zygotes derived from 4 - to 8 -week-old BDF1 (C57BL/6 $\times \mathrm{DBA} / 2)$ female mice. In one case, the transgenic (Tg) line TRE-PC3 family L, the $2.05 \mathrm{~kb} P v u \mathrm{I}-H i n d I I I$ fragment of TRE- $P C 3$ was used for injection. Injected embryos were transferred to the oviducts of pseudopregnant BDF1 foster females aged 2-8 months, as described previously (Hogan et al., 1995). The production and characterization of mice carrying the rtTA transgene under the control of nestin promoter has been described previously (Mitsuhashi et al., 2001).

Screening of transgenic mice was performed by PCR for routine genotyping and by Southern blot analysis to define copy number and structure of the transgenes, using genomic DNA from tail tips or from the yolk sac of embryos. Copy number was determined by densitometric analysis, using the full XhoI-HindIII fragment of the transgene as an internal hybridization standard. Primers used to identify $\beta$ ACT-tTA or nestinrtTA transgenic animals amplified 991 bp of the tTA transgene are as follows: $\mathrm{ftTA} 2(+)$ (5'-AAGTAAAGTGATTAACAGCGC-3') and rtTA2 $(-)$ (5'-CTACCCACCGTACTCGTC- $\left.3^{\prime}\right)$, whereas primers $P C 3$ 123-142(+) (5' ${ }^{\prime}$-TCACCAGTCTCCTGAGGACT-3') and pUHD10-3530-506 (-) (5'-AGTTGTGGTTTGTCCAAACTCATC-3') were used to identify TRE- $P C 3$ transgenic animals and amplified a 507 bp fragment. Doxycycline hydrochloride ( $2 \mathrm{mg} / \mathrm{ml}$; Sigma, St. Louis, MO) was supplied in the drinking water (supplemented by $5 \%$ sucrose).

$R N A$ extraction, semiquantitative reverse transcription- $P C R$, and realtime reverse transcription- $P C R$. Total cellular RNA was extracted according to Chomczynski and Sacchi (1987) and was analyzed by semiquantitative reverse transcription (RT)-PCR as described previously (Guardavaccaro et al., 2000). Briefly, $10 \mu \mathrm{g}$ of total RNA were treated with DNase (RQ1; Promega, Madison, WI), denatured at $75^{\circ} \mathrm{C}$ for $5 \mathrm{~min}$, and added to a final reaction volume of $50 \mu$ l. Half of the reaction volume was then incubated for $2 \mathrm{hr}$ at $37^{\circ} \mathrm{C}$ with Moloney murine leukemia virus-RT (Promega). The remaining half of the volume without RT was used as control in PCR amplifications for possible contamination by genomic DNA. Two microliters of each RT reaction were then used for PCR amplification in a $100 \mu \mathrm{l}$ PCR reaction. The number of PCR cycles was designed so as to maintain the reactions of amplification in the exponential phase ( 25 cycles for $18 \mathrm{~S}$ RNA and 35 cycles for the other templates). 18 S RNA was coamplified to measure the efficiency of the reaction and the RNA amount in each sample. The amplification profile was as follows: $94^{\circ} \mathrm{C}$ for $5 \mathrm{~min}$, followed by cycling through $94^{\circ} \mathrm{C}$ for 1 $\min , 62^{\circ} \mathrm{C}$ for $1.5 \mathrm{~min}, 72^{\circ} \mathrm{C}$ for $1.5 \mathrm{~min}$, with a final step of $72^{\circ} \mathrm{C}$ for 10 min. PCR products were gel separated, blotted to a nylon filter, and hybridized with $\left[{ }^{32} \mathrm{P}\right]$-labeled oligonucleotides, whose sequence was internal to the region amplified by PCR. PCR primers used were as follows: for transgenic PC3, forward (5'-TCACCAGTCTCCTGAGGACT-3'), backward (5'-AGTTGTGGTTTGTCCAAACTCATC-3') [this latter primer, being reverse complementary to the $\mathrm{SV} 40$ poly(A) region in the TRE-PC3 construct, amplifies only PC 3 exogenous transcript]; for selective amplification of endogenous PC3(Tis21), forward (5'TCTCCAGTCTCCTGAGGACT-3'), backward (5'-ATGAGAACAGTAGAGTGCCAGG-3'); 18 S RNA, forward ( $5^{\prime}$-TTTCGGAACTGAGGCCATGATTAAG-3'), backward (5'-AGTTTCAGCTTTGCAACCATACTCC-3'). Primers for RT-PCR-Southern blot analysis of Math1, NeuroD1, Zic1, Zipro1, p21, and p27 mRNA levels in granule cells in vitro were deduced from published murine cDNA sequences. RT-PCR products were identified by Southern blot hybridization and visualized with a Molecular Dynamics (Sunnyvale, CA) 400A PhosphorImager system. The levels of total RNA extracted from E14 cerebella of Math1 $\beta$ galactosidase $(\beta$-gal)/ $\beta$-gal (Math1 null) (Ben-Arie et al., 2000) and

\footnotetext{
Figure 1. Generation and genomic analyses of transgenic mice with regulated expression of $P(3 . A$, TRE- $P$ C 3 transgene contains tet operator sequences (TRE) fused upstream to the minimal CMV promoter (pCMVmin), PC3 ORF, and the late SV40 gene polyadenylation site (pA). B, $\beta$ ACT-tTA transgene includes human $\beta$-actin promoter fused to the $\beta$-actin IVS1/splice acceptor, human CMV promoter- enhancer, tetR/VP16 transactivator (tTA), and the 3' UTR of the human $\beta$-actin gene with pA. Mechanisms of conditional activation are outlined in Materials and Methods. C, Southern blot analysis of the genomic organization of TRE-PC3 in transgenic mice. Xbal-digested tail DNA of Tg TRE-PC3 mice was hybridized with the indicated probes. Tg TRE-PC3 A and G had clearly unique junctional fragments, indicating a single site of integration. White arrowheads indicate DNA fragments containing the regions flanking the integration site depicted in $D$ (left). The $L$ family element has higher size because it included $0.6 \mathrm{~kb}$ of pUHD10-3 vector. D, Genomic organization of the TRE-PC3 transgene. $E$, Analysis of expression of Tg $\beta$ ACT-tTA in mice lineages, measured by luciferase activity in lysates from indicated organs obtained from 4- to 5-week-old mice carrying the following: no transgene (WT); Tg TRE-Luc (L7 strain); binary Tg CMV-rtTA/TRE-Luc; binary Tg $\beta$ ACT-tTA (strain nACT37)/TRE-Luc; and binary Tg $\beta$ ACT-tTA (strain nACT75)/TRE-Luc. Luciferase units per milligram of extract protein are expressed as mean \pm SEM, and the number of animals is indicated. N.D., Not determined.
} 


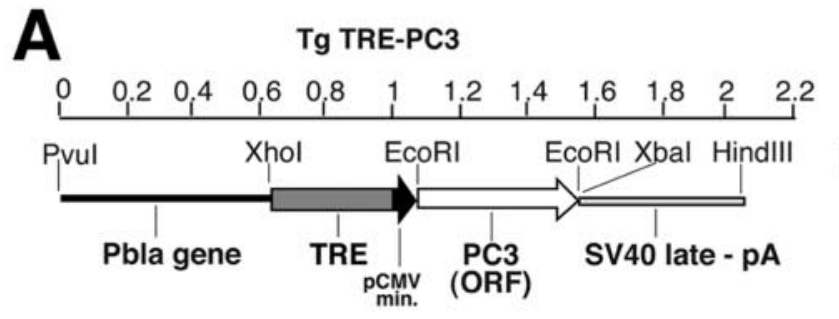

C

A C G L

PC3
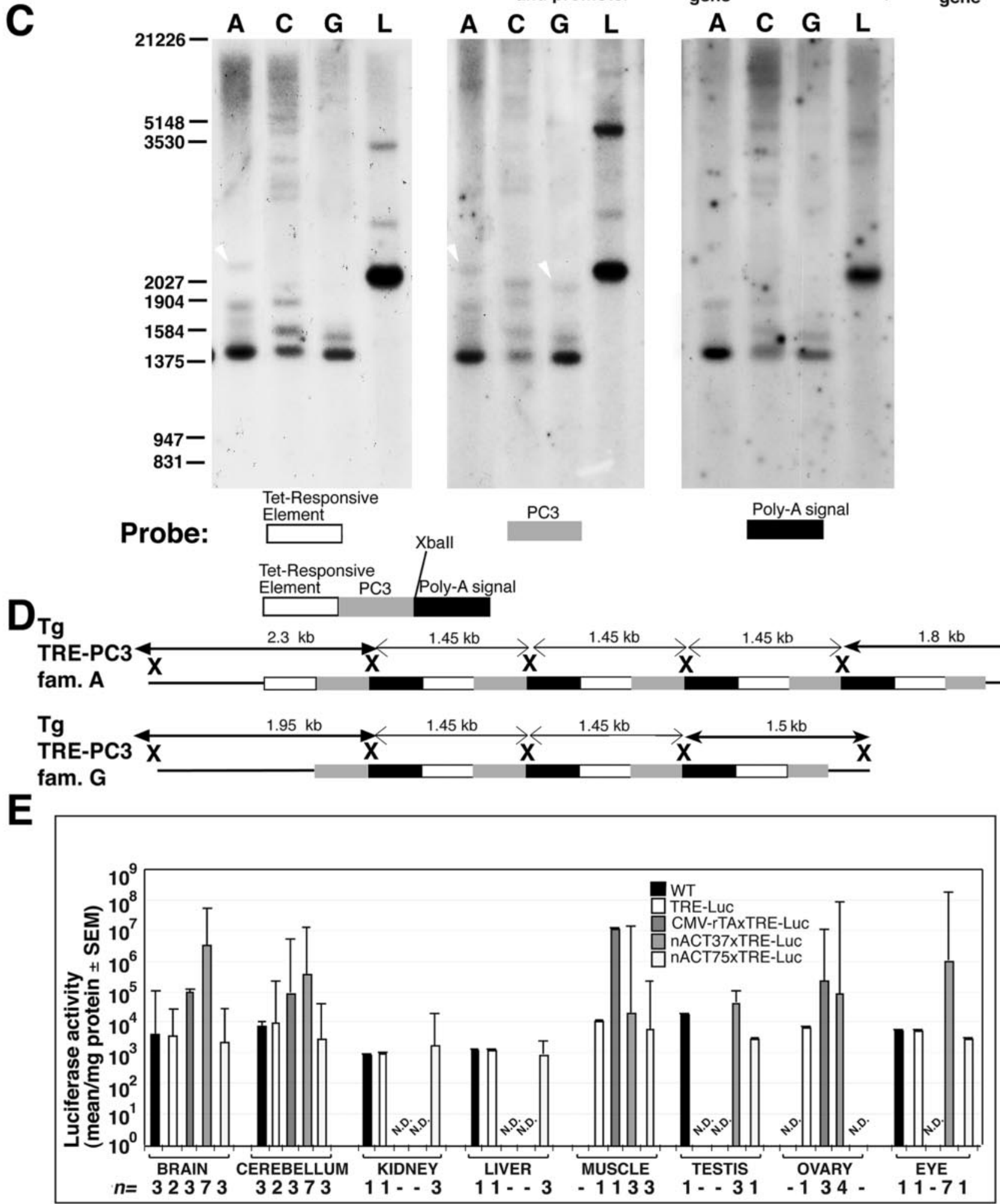

Tg BACT-tTA

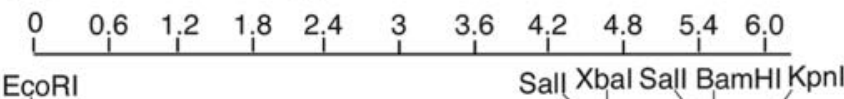

h $\beta$ actin

5' UTR

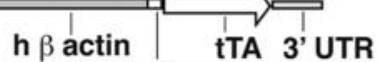

genomic sequence

h $\beta$ actin IVS1

gene

A C G L

splice acceptor

gene 
Math1+/+ (wild-type) littermates were measured by real-time RT-PCR amplifications, performed with primers specific to Math1, PC3, and actin (primer sequences are available on request) in a Rotor-Gene thermocycler (Corbett Research, Sydney, Australia).

Animal treatment. Animals were housed under a $12 \mathrm{hr}$ light/dark schedule. E1 was considered completed at midnight of the day after mating. Embryos were fixed in utero by transcardiac perfusion with $4 \%$ paraformaldehyde (PFA) in PBS-DEPC. After dissection, embryos were kept overnight at $4^{\circ} \mathrm{C}$ in PFA. Embryos used for sectioning were cryoprotected in $30 \%$ sucrose in PBS-DEPC overnight at $4^{\circ} \mathrm{C}$ and frozen at $-80^{\circ} \mathrm{C}$ until use. Postnatal day $1(\mathrm{P} 1)$ and $\mathrm{P} 5$ brains were fixed by immersion in PFA overnight at $4^{\circ} \mathrm{C}$. For whole-mount in situ hybridization (ISH) analysis, embryos were stored after fixation in methanol at $-20^{\circ} \mathrm{C}$.

Immunohistochemistry, antibodies, bromodeoxyuridine labeling, and terminal deoxynucleotidyl transferase-mediated biotinylated UTP nick end labeling analysis. Immunohistochemistry was performed on sections using mouse monoclonal antibodies raised against $\beta$ III tubulin (1:75; Promega), neurofilament 68 (NF68) and 160k (NF160) (1:40; Sigma), MAP-2 (microtubule-associated protein-2; clone HM-2; 1:100; Sigma), cyclin D1 (clone 72-13G; 1:75; Santa Cruz Biotechnology, Santa Cruz, CA), and calbindin (clone CB-955; 1:200; Sigma) or using rabbit polyclonals that recognize GFAP (1:100; Promega), Math1 (1:70; Chemicon, Temecula, CA), NeuroD1 (1:150; Chemicon), N-myc (SC-791; 1:50; Santa Cruz Biotechnology), and PC3 (A3H) (Guardavaccaro et al., 2000). $\mathrm{A} 3 \mathrm{H}$ antibody did not distinguish between transgenic $P C 3$ and the endogenous mouse PC3 (i.e.,Tis21) proteins. Primary antibody binding was revealed using FITC-conjugated goat anti-mouse or tetramethylrhodamine isothiocyanate (TRITC)-conjugated goat anti-rabbit secondary antibodies (1:100 and 1:200, respectively; Jackson ImmunoResearch, West Grove, PA). Hybridized and immunostained sections were viewed using an Olympus Optical (Tokyo, Japan) BX51 microscope, and laserscanning confocal microscopy was performed using a Leitz DMR microscope connected to a confocal Leica (Nussloch, Germany) TCS system.

For bromodeoxyuridine (BrdU) incorporation, pregnant mice were injected with $\mathrm{BrdU}$ ( $90 \mathrm{mg} / \mathrm{kg}$, i.p.) 1 or $1.5 \mathrm{hr}$ before being killed to analyze the neural tube of E12 embryos or the EGL at P1-P5. These periods of incorporation were considered appropriate to label mainly $S$ phase cells given that, in neuroepithelial cells of the neural tube of E12 embryos, the duration of $S$ phase is $\sim 5.5 \mathrm{hr}$ and the whole cycle is $10 \mathrm{hr}$ (Kauffman, 1968), whereas in GCPs of P1-P5 mice, the duration of S phase is $\sim 7 \mathrm{hr}$, of $\mathrm{G}_{2} / \mathrm{M} 3.5 \mathrm{hr}$, and the whole cycle $16 \mathrm{hr}$ (Mares et al., 1970). Sections were treated with $0.1 \mathrm{~N} \mathrm{HCl}$ for $20 \mathrm{~min}$ at $37^{\circ} \mathrm{C}$ and then in sodium borate for $15 \mathrm{~min}$ at room temperature and permeabilized in $0.3 \%$ Triton X-100 (10 min). The samples were reacted with mouse monoclonal anti-BrdU (Amersham Biosciences, Arlington Heights, IL) 1 $\mathrm{hr}$ at room temperature, followed by FITC-conjugated goat anti-rabbit secondary antibody (F9006; 1:100; Sigma) diluted 1:100 and counterstained by Hoechst 33258 ( $1 \mathrm{mg} / \mathrm{ml}$ in PBS; Sigma) to detect nuclei. The BrdU labeling index (BrdULI) (percentage ratio of the number of BrdUlabeled cells to the total number of cells) was calculated for the entire length of the EGL in each photomicrograph field, from digital images obtained through a Diagnostic Instruments (Sterling Heights, MI) camera 1.3.0, connected to an Olympus Optical BX51 microscope, and analyzed by the I.A.S. software (Delta Sistemi, Rome, Italy). The EGL area and the density of cells per area were analyzed similarly. Nuclei with condensed and fragmented chromatin were considered apoptotic (Oberhammer et al., 1992) and were not counted. Terminal deoxynucleotidyl transferase-mediated biotinylated UTP nick end labeling (TUNEL) (Gavrieli et al., 1992) was performed on cryostat sections using the in situ cell death detection kit (Roche Products, Hertforshire, UK), according to the instructions of the manufacturer. Apoptotic nuclei were visualized with $0.5 \%$ DAB. Western blot analysis, performed as described previously (Guardavaccaro et al., 2000), was performed on cerebella obtained from $\mathrm{P} 1$ mice and homogenized in lysis buffer ( $50 \mathrm{~mm}$ Tris- $\mathrm{HCl}, \mathrm{pH} 7.4$, $1 \mathrm{~mm}$ EDTA, $150 \mathrm{~mm} \mathrm{NaCl}$, and $0.7 \% \mathrm{NP}-40$, with protease inhibitors). Proteins (100 $\mu \mathrm{g} /$ lane) were electrophoretically separated by SDS- $10 \%$ PAGE and transferred to nitrocellulose. The filter was incubated with primary antibodies [anti-cyclin D1, clone 72-13G, 1:100 (Santa Cruz Biotechnologies); anti-cyclin D2, clone DCS-3, 1:400 (Sigma); anti-cyclin
D3, clone SC-182, 1:200 (Santa Cruz Biotechnology)] and incubated with the secondary antibody, followed by a chemiluminescent detection.

In situ hybridization. Preparation of sections and hybridization were performed as reported previously (Tata, 2001). Antisense riboprobes specific for transgenic PC3 mRNA were synthesized by T7 polymerase (Roche Products), from either the SV40 polyadenylation region of the TRE-PC3 transcript (200 bp long, cloned into pcDNA3 vector, restricted by HindIII) or the CMV minimal promoter region unique to TRE-PC3 transcript ( $80 \mathrm{bp}$ long, cloned into pcDNA3 vector). Antisense riboprobes detecting cyclin D2 and cyclin D3 mRNAs were synthesized by T7 polymerase from mouse cyclin D2 cDNA or by T3 polymerase from mouse cyclin D3 cDNA (Matsushime et al., 1991). Riboprobes were labeled with biotin-UTP or digoxigenin-UTP (Transcription kit; Roche Products) per the protocol of the manufacturer. No signal was detected by sense probes. Endogenous PC3 (i.e., Tis21) and Math1 transcripts were detected by oligonucleotides (sequences available on request) labeled with biotin-dUTP, using the terminal transferase method (oligonucleotide tailing kit; Roche Products) per the protocol of the manufacturer. The oligonucleotides detecting the endogenous $P C 3$ transcript did not cross-hybridize with the exogenous transcript, being complementary to a region of $P C 3$ mRNA not encoded by the transgene.

Hybridization was performed at $37^{\circ} \mathrm{C}$, followed by standard washes in SSC at $37^{\circ} \mathrm{C}$. After signal amplification by biotinyl-tyramide (TSA biotin system; PerkinElmer Life Sciences, Emeryville, CA) as described previously (Tata, 2001), the reaction products were identified with 3.3'diaminobenzidine. No signal was detected using sense oligonucleotides. Whole-mount ISH on E12 embryos was performed according to Wilkinson (1992), using a digoxigenin-UTP-labeled transgenic PC3-specific antisense riboprobe. Hybridization was performed at $65^{\circ} \mathrm{C}$ for $18 \mathrm{hr}$. Samples were incubated overnight at $4^{\circ} \mathrm{C}$ with alkaline phosphataseconjugated anti-digoxigenin antibody (1:2000; Roche Products), washed, and processed for colometric detection using 5-bromo-4-chlor-indolylphosphate/nitroblue-tetrazolium-chloride.

Cell culture, recombinant adenoviruses, and Math1 promoter functional assay. Cerebellar granule cultures from Wistar 8- and 2-d-old rats were prepared as described previously (Levi et al., 1989). The postmitotic state of cell cultures was verified by BrdU incorporation. Recombinant adenovirus-expressing PC3 was produced using the Adeno-X expression system (Clontech, Cambridge, UK), by cloning into the Adeno- $\mathrm{X}$ viral DNA the PC3 ORF, excised from the vector pShuttle. $\beta$-Galactosidase and p27 adenoviruses were kindly provided by M. Crescenzi (Instituto Superiore Di Sanitá, Rome, Italy), and p21-expressing adenovirus was provided by M. Grossi (Università La Sapienza, Rome, Italy). Adenoviruses were propagated in HEK293 cells as described by Latella et al. (2001). Viral titer was determined by plaque formation assay using HEK293 cells. Recombinant adenoviruses with titers in the range of $10^{8}$ $10^{9} \mathrm{pfu} / \mathrm{ml}$ were routinely obtained. Infection of granule cells was performed for $1 \mathrm{hr}$. Transfection of PC12 cells was performed according to Corrente et al. (2002), and measurement of luciferase reporter activity of mouse Math1 promoter and enhancer regions was according to Guardavaccaro et al. (2000). Primary cerebellar granule cell cultures were transfected by electroporation with a Gene Pulser II apparatus (Bio-Rad, Hercules, CA) using a cuvette (catalog \#165-2088; Bio-Rad) containing $2.5 \times$ $10^{6}$ granule cells in a volume of $400 \mu \mathrm{l}$ of basal medium Eagle without serum, with discharge potential set at $200 \mathrm{~V}$ and $950 \mu \mathrm{F}$. The cells contained in each cuvette were then plated in $35 \mathrm{~mm}$ culture dishes and lysed after $24 \mathrm{hr}$ for luciferase assay. The Math 1 promoter region was obtained by PCR amplification of the region comprising 1379 nucleotides (nt) upstream to the ATG, of which $\sim 170$ nt belong to the $5^{\prime}$ untranslated mRNA sequence (Akazawa et al., 1995), and was cloned in SacI-XhoI sites of pGL3 (pGL3-Math1-pr/-1200). The Math1 enhancer was obtained by PCR amplification of the Math1 gene [sequence identified as nt 1-1385 (Helms et al., 2000, their construct \#9)] and was cloned in KpnI-SacI sites of pGL3, upstream to a minimal $\beta$-globin promoter (pGL3-Math1-enh).

\section{Results}

Generation of inducible $P C 3$ transgenic mice

To test the hypothesis that $P C 3$ plays a critical role in the differentiation of neuronal progenitors, we produced mice carrying a 
Table 1. Phenotype of transgenic $\beta$ ACT-tTA and TRE-PC3 mice

\begin{tabular}{|c|c|c|c|c|c|c|c|c|c|c|c|c|c|c|}
\hline \multirow[t]{2}{*}{ Transgene 1} & \multirow[t]{2}{*}{ None (WT) } & \multirow[t]{2}{*}{ nACT-tTA } & \multicolumn{12}{|c|}{ Tg TRE-PC3, families } \\
\hline & & & A & G & $C$ & L & A & G & $C$ & L & A & $G$ & $C$ & L \\
\hline Transgene 2 & None (WT) & None (WT) & A & G & WT & WT & nACT-tTA + & doxycycline & & & nACT-tTA - d & oxycycline & & \\
\hline \multicolumn{15}{|l|}{ Phenotype } \\
\hline Normal & $100.0 \pm 0.0$ & $100.0 \pm 0.0$ & $97.2 \pm 2.7$ & $100.0 \pm 0.0$ & $100.0 \pm 0.0$ & $100.0 \pm 0.0$ & $98.1 \pm 1.8$ & $100.0 \pm 0.0$ & $100.0 \pm 0.0$ & $100.0 \pm 0.0$ & $46.3 \pm 8.8$ & $63.9 \pm 10.1$ & $87.5 \pm 12.5$ & $90.9 \pm 9.1$ \\
\hline $\mathrm{DL} ; \mathrm{D} ; \mathrm{DA} ; \mathrm{DG}$ & $0.0 \pm 0.0$ & $0.0 \pm 0.0$ & $2.7 \pm 2.7$ & $0.0 \pm 0.0$ & $0.0 \pm 0.0$ & $0.0 \pm 0.0$ & $1.9 \pm 1.8$ & $0.0 \pm 0.0$ & $0.0 \pm 0.0$ & $0.0 \pm 0.0$ & $44.6 \pm 9.9^{*}$ & $30.1 \pm 8.1^{*}$ & $12.5 \pm 12.0$ & $9.1 \pm 9.0$ \\
\hline DS & $0.0 \pm 0.0$ & $0.0 \pm 0.0$ & $0.0 \pm 0.0$ & $0.0 \pm 0.0$ & $0.0 \pm 0.0$ & $0.0 \pm 0.0$ & $0.0 \pm 0.0$ & $0.0 \pm 0.0$ & $0.0 \pm 0.0$ & $0.0 \pm 0.0$ & $2.4 \pm 2.3$ & $0.0 \pm 0.0$ & $0.0 \pm 0.0$ & $0.0 \pm 0.0$ \\
\hline VS & $0.0 \pm 0.0$ & $0.0 \pm 0.0$ & $0.0 \pm 0.0$ & $0.0 \pm 0.0$ & $0.0 \pm 0.0$ & $0.0 \pm 0.0$ & $0.0 \pm 0.0$ & $0.0 \pm 0.0$ & $0.0 \pm 0.0$ & $0.0 \pm 0.0$ & $6.7 \pm 2.5^{*}$ & $6.0 \pm 2.9^{*}$ & $0.0 \pm 0.0$ & $0.0 \pm 0.0$ \\
\hline Litters, number & 14 & 14 & 6 & 5 & 2 & 6 & 9 & 3 & 2 & 2 & 21 & 7 & 2 & 2 \\
\hline
\end{tabular}

Transgene 1 and 2 were crossed as indicated. DL, Dead for reduced milk intake; D, born dead; DA, dead after few hours; DG, dead after few days; DS, born dead and very small; VS, very small. * $p<0.05$ versus control. Student's $t$ test.

PC3 transgene. We chose the conditionally regulated binary teton/off system for its versatile spatiotemporal control of gene expression through a tetracycline-responsive tissue-specific promoter (Kistner et al., 1996). The first transgenic mice we generated, Tg TRE-PC3 (Fig. $1 A$ ), carried the coding region of the rat $P C 3 \mathrm{cDNA}$, conditionally able to be activated under the control of the tetracycline-responsive element (referred to as TRE here, or as TetO by Kistner et al., 1996).

To activate the expression of Tg TRE- $P C 3$ required breeding with a second transgenic mouse carrying the tTA, under the control of a promoter of choice (see also Materials and Methods). We chose to drive the expression of the exogenous PC3 from early developmental stages, before the activation of endogenous PC3 expression, and preferentially, but not exclusively, in neuronal tissues, similarly to the expression of endogenous PC3. We thus generated a second transgenic line, Tg $\beta$ ACT-tTA, carrying the tTA coding sequence under the control of a $\beta$-actin promoter that satisfied the requirement of early and mainly neuronal expression (Fig. 1B). As a complementary approach to test our hypothesis, we also targeted the expression of $P C 3$ specifically to neuroepithelial cells using a previously described transgenic line expressing a tetracycline-regulated transactivator under the control of the nestin promoter, which is active in neuronal progenitors (Tg nestin-rtTA) (Mitsuhashi et al., 2001).

Thus, four Tg TRE-PC3 lines (A, C, G, and L) were generated (Fig. 1A). As judged by viability, phenotype, body weight, and number of progeny, these lineages did not differ from wild type (Table 1, and data not shown). Therefore, we excluded alterations arising from either possible toxic effects of the TRE- $P C 3$ sequence per se or its genomic insertion loci. Southern blot analysis, performed using different fragments of the transgene as probes, indicated that the transgene element was inserted in families $\mathrm{A}, \mathrm{C}$, $\mathrm{G}$, and $\mathrm{L}$ of Tg TRE-PC3, in tandem repeats of $6,3,5$, and 10 copies, respectively (Fig. 1C,D). Flanking integration fragments were identified and appeared clearly unique for TRE-PC3 A and $G$, indicating a unique integration site of the transgene (shown with the structural organization in Fig. 1D). The transgene appeared stable, as assessed by Southern blot analysis, routinely performed throughout new generations.

Eight Tg $\beta$ ACT-tTA mice lines were also generated, carrying a transgene in which the human $\beta$-actin promoter drives the expression of the tTA sequence (Fig. $1 B$ ), and these were analyzed by crossing the Tg $\beta$ ACT-tTA strains with a luciferase standard responder (Tg TRE-Luc, named L7 indicator) (Kistner et al., 1996). Luciferase activity was measured in homogenates of different organs from the bitransgenic mice. Mice with no transgene and of the L7 strain were used as negative controls, whereas a positive control was obtained by breeding the CMV-rtTA strain (Kistner et al., 1996) with the L7 indicator (binary Tg CMV-rtTA/ TRE-Luc). We identified a Tg $\beta$ ACT-tTA mice lineage (named
$\mathrm{nACT} 37)$ in which the $\beta$-actin promoter was active mainly in the brain, cerebellum, and eye, from the early stages of development to adulthood (A. Servadio, unpublished data). In fact, the levels of luciferase activity in brain, cerebellum, and eye were $\sim 1000$-, 40-, and 200-fold higher, respectively, than in the L7 control mice tissues (Fig. $1 E$ ). A strain with no increase of luciferase activity above L7 control mice was also identified (nACT75) (Fig. 1E). No toxic side effects of tTA in the Tg $\beta$ ACT-tTA lineage nACT37 were detected by analyzing viability, phenotype, and body weight (Table 1 and data not shown).

\section{PC3 binary transgenic mice display lethality, dwarfism, and altered neurogenesis}

To induce the expression of $P C 3$, lineages $\mathrm{A}, \mathrm{C}, \mathrm{G}$, and $\mathrm{L}$ of the $\mathrm{Tg}$ TRE-PC3 were crossed with the Tg $\beta$ ACT-tTA (lineage nACT37). In the absence of doxycycline (a tetracycline analog), the bitransgenic $\beta$ ACT-tTA/TRE-PC3 animals produced the transcription transactivator TTA, which could bind the TRE element within TRE-PC3 to trigger expression of the exogenous $P C 3$. Conversely, doxycycline inactivated tTA and thus repressed expression of the exogenous $P C 3$. We monitored the phenotype, viability, body weight, and number of the progeny after continuous expression of the exogenous PC3 (Fig. 2A-E; Table 1; and data not shown) and analyzed its expression pattern by RT-PCR in the offspring and by whole-mount ISH in embryos (Fig. 3A$D)$. When mice were kept continuously under doxycycline treatment, the progeny was normal (Table 1).

In contrast, the progeny of bitransgenic mice of lineages $A$ and $G$, which were never exposed to doxycycline (thus with active transcription of transgenic PC3 since conception), presented a significant percentage of death at birth and a reduced size. The surviving mice usually did not reach adulthood, but, when this occurred, a slower growth rate was observed, associated with abnormal posture and gait and an incomplete development of the cerebellum (Table 1; Fig. $2 A-C$ ). The cerebellar folia were less deep and the lobules were of smaller size and length, particularly in the vermis (lobules VIII and IX) and rostrally (lobules IV and $\mathrm{V})$ (Fig. 2D,E). Moreover, the reduction in size was more pronounced in the cerebellum than in the whole brain (55 vs 30\%) (Fig. $2 D, E$ ). The motility of the surviving Tg $\beta$ ACT-tTA/TRE$P C 3$ mice was markedly reduced, accompanied by ataxic gait and extension of the lower limbs as early as P10. The frequent appearance of reduced size and weight in bitransgenic $\beta$ ACT-tTA/TREPC3 families G and A (Table 1; Fig. 2C) was consistent with the high copy number and the unique integration site of TRE-PC3 elements in the genome. Thus, families A and G of Tg TRE-PC3 were chosen for additional study and considered equivalent.

High expression of exogenous $P C 3$, comparable with that of the endogenous PC3, was observed by RT-PCR on E13 embryos (head) of bitransgenic mice lineages A and G (Fig. $3 A, B$ ). Whole- 


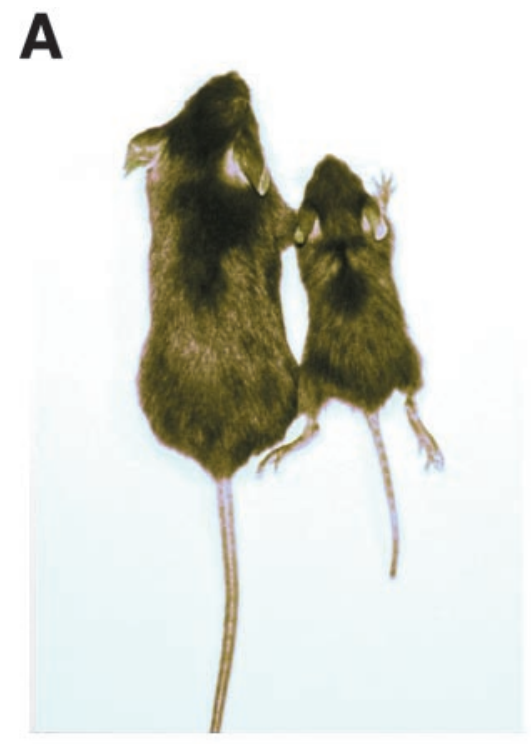

B
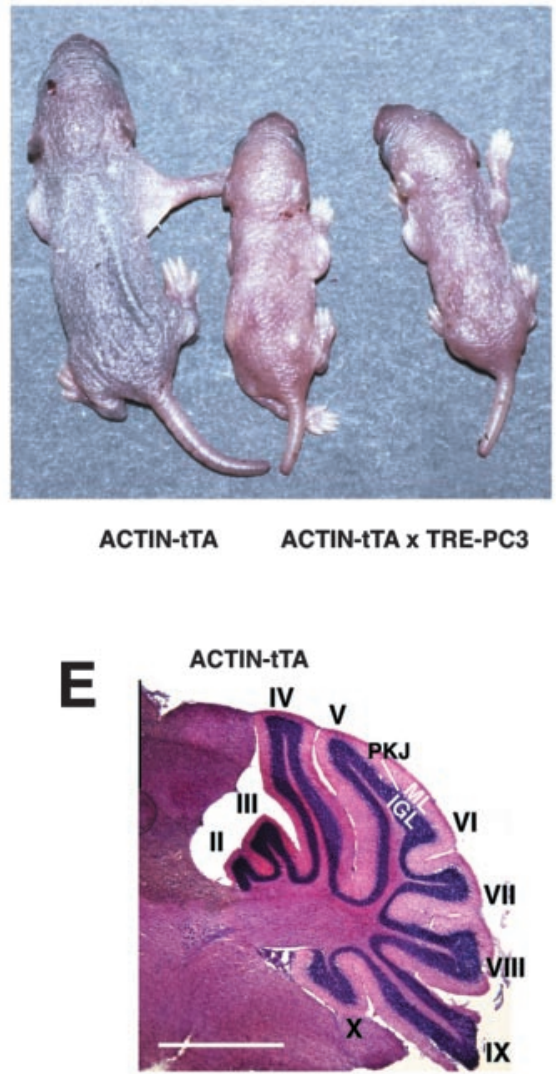

C
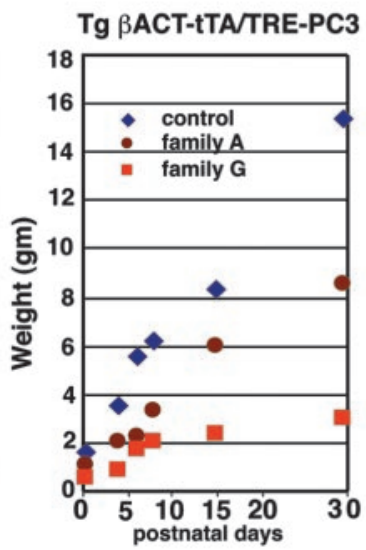

ACTIN-tTA $\times$ TRE-PC3

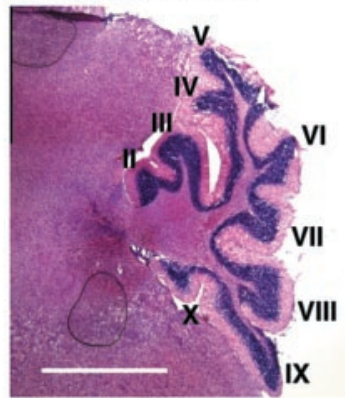

Figure 2. Bitransgenic $\beta$ ACT-tTA/TRE-PC3 mice display reduced body and cerebellar size and ataxic gait. $A$, Normal-sized Tg TRE-PC3 (left) and a binary Tg $\beta$ ACT-tTA/TRE-PC3 of smaller size (right). Both are $30 \mathrm{~d}$ old and were never exposed to doxycycline. B, Newborn TRE-PC3 mouse of normal size (left) and bitransgenic Tg $\beta A C T-t T A / T R E-P C 3$ mice of small size (right). C, A representative weight curve of $\beta$ ACT-tTA/TRE-PC3 mice, families A and G; the control is a bitransgenic treated with doxycycline that did not differ from wild type. $D$, Brain of mice shown in $A$. The cerebellar vermis is absent in Tg $\beta$ ACT-TTA/TRE-PC3 (right). E, Hematoxylin and eosin staining of cerebella from mice shown in $A$, revealing a reduced length and size of lobules in bitransgenic compared with single transgenic and a selective reduction of cerebellar size. Scale bars, $750 \mu \mathrm{m}$. PKJ, Purkinje cell layer; ML, molecular layer.

mount ISH performed on E12 bitransgenic embryos indicated that exogenous PC3 transcription was under the control of doxycycline, mainly in the telencephalon, rhomboencephalon, retinal primordium, spinal cord, and dorsal root ganglia, but also in paws and to a lower extent in viscera (Fig. 3D). No evidence of altered morphology of the embryo at E12 could be observed (Fig. $3 D$, left). This spatial distribution indicated that, in Tg $\beta A C T$ tTA/TRE-PC3, the expression pattern of the exogenous PC3 in the CNS was similar to that of the endogenous PC3 (Iacopetti et al., 1994). Furthermore, when the expression of exogenous PC3 was activated $\sim 1$ week after birth (by removing doxycycline at birth, given the lag for metabolization of maternal doxycycline), the progeny was normal (data not shown). In these animals, at P40, exogenous PC3 expression was detected by RT-PCR analysis, with a pattern similar to that detected previously by luciferase assay in the Tg $\beta$ ACT-tTA lineage nACT37 (high expression in brain and cerebellum and low or no expression in muscle) (Fig. $3 C$ and data not shown). As a whole, the above results suggested that the expression of exogenous PC3 affected the viability and embryonic development acting after E12 and possibly until the first postnatal week, which raised the possibility of a negative selection of embryos that highly expressed transgenic PC3.

As a complementary approach, we examined the effect of targeting PC3 to neuroepithelial cells, crossing the Tg TRE-PC3 lineages A and G with Tg nestin-rtTA (Mitsuhashi et al., 2001). In this mouse model, doxycycline stimulates a modified tTA transactivator (rtTA), causing the activation of the transgene in binary mice (Kistner et al., 1996). Whole-mount ISH performed in E12 bitransgenic embryos indicated that doxycycline-induced transgenic PC3 mRNA was expressed almost exclusively in proliferating neuroepithelia of CNS and PNS (Fig. 3D, right panels) (Mitsuhashi et al., 2001). No overt alteration of phenotype was observed in newborn and adult bitransgenic mice. However, CNS analysis revealed a number of alterations in the development of the neural tube and of the cerebellum, which are described below.

Expression of $P C 3$ in the neural tube inhibits cell cycle and increases differentiation of neuronal progenitors

In Tg nestin-rtTA/TRE-PC3, a strong expression of the doxycyclineinduced exogenous $P C 3$ was detected at E12.5 in the neural tube and dorsal root ganglia and to a lesser extent in the cranial nerve ganglia, in which the endogenous PC3 is normally present (Iacopetti et al., 1994) (Fig. 4A,F). To verify whether overexpression of PC3 affected neurogenesis, we examined differentiation of the neuronal progenitors in these regions. Strikingly, $P C 3$ overexpression led to an increment of $\beta$ III tubulin and MAP-2-positive cells (Fig. $4 B, C, G, H$ ). This was particularly evident in the neural tube, in which most of the neuroblasts were highly positive for both $P C 3$ and $\beta I I I$ tubulin (Fig. $4 B, G, K, L)$. Concomitantly, a marked decrease of BrdU incorporation was evident in the VZ of the neural tube of the activated Tg (Fig. 
A

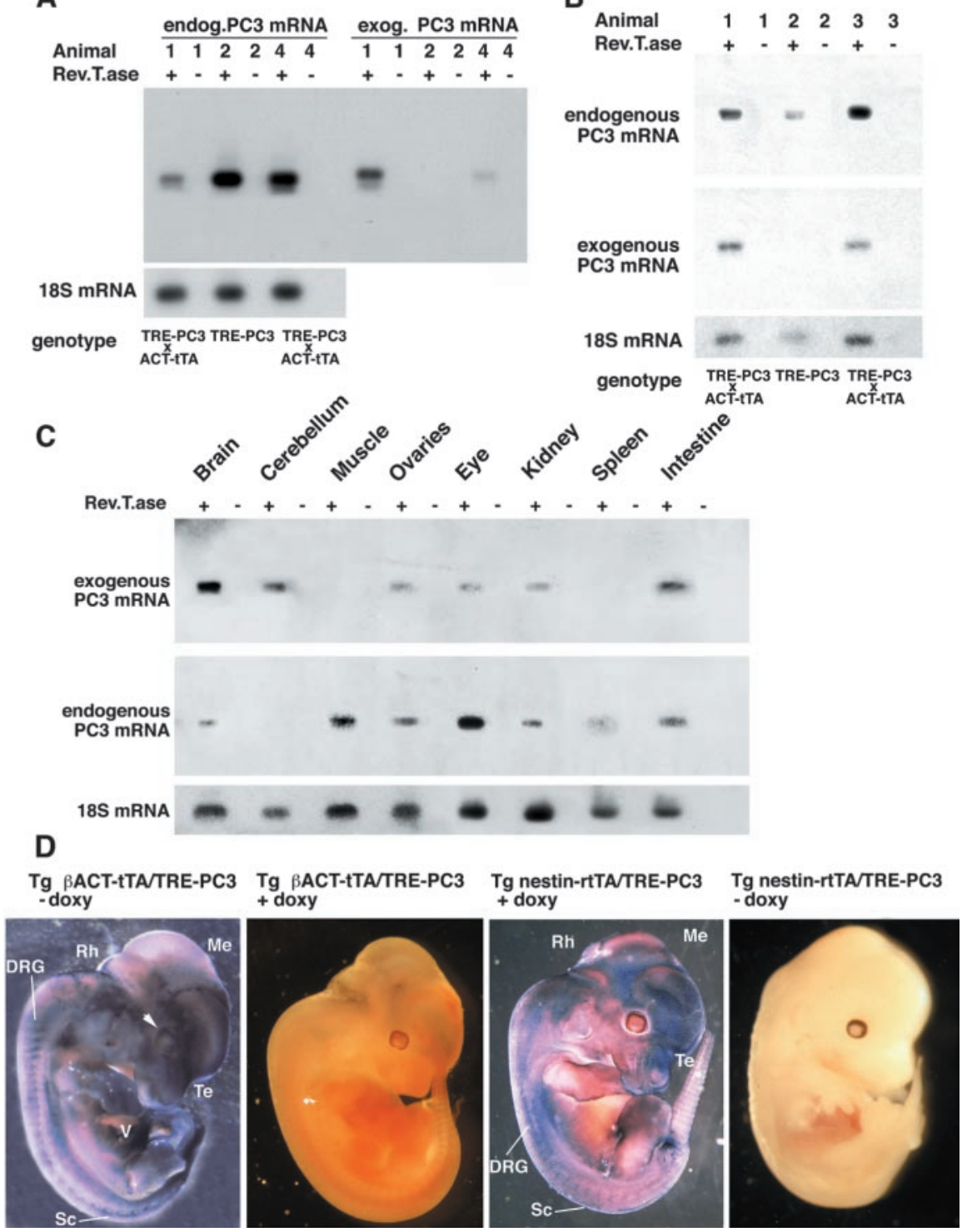

Figure 3. Regulated $P C 3$ transgene expression in Tg $\beta$ ACT-tTA/TRE- $P C 3$ mice and selective targeting to neuroepithelia in $\mathrm{Tg}$ nestin-tTA/TRE-PC3. $A, B$, Semiquantitative RT-PCR of exogenous and endogenous $P C 3 \mathrm{mRNA}$ was performed on RNA from heads of E13 embryos, obtained by breeding $\operatorname{Tg} \beta$ ACT-TTA with Tg TRE-PC3 family A $(A)$ or family $G(B)$. Equal amounts of RT-PCR amplified products were electrophoresed, blotted on filters, and hybridized to $\left[{ }^{32} P\right]$-labeled probes for transgenic $P(3$, endogenous $P(3$, and 185 mRNA. RT + or - refers to the products of amplification performed in parallel on aliquots of each RNA sample, preincubated or not with RT, as controls for the presence of DNA contamination. C, RT-PCR analysis of PC3 mRNA in various tissues from 40-d-old bitransgenic $\beta$ ACT-tTA/TRE-PC3 mice exposed to doxycycline ( $250 \mu \mathrm{g} / \mathrm{ml}$ of drinking water) from 1 week before fertilization until birth, to allow only postnatal expression. D, Whole-mount ISH of E12 embryos from Tg $\beta$ ACT-TTA/TRE-PC3 and Tg nestin-tTA/TRE- $P C 3$, without or with doxycycline, respectively, or control. A transgenic $P C 3$-specific antisense riboprobe was used. Te, Telencephalon; Me, mesencephalon; $\mathrm{Rh}$, rhomboencephalon; $\mathrm{Sc}$, spinal cord; DRG, dorsal root ganglia; $\mathrm{V}$, viscera. Arrow indicates the retinal primordium.

$4 D, I)$, indicating a decreased proliferation of neuroepithelial cells. Quantitative analysis of the ratio of $\beta$ III tubulin ${ }^{+}$cells/total number of cells in the neural tube revealed an increase of approximately twofold compared with control mice (Fig. 4M). Moreover, the ratio of neural tube cells positive for both $\beta$ III tubulin and $P C 3 /$ total number of cells (a measure that correlated the expression of $\beta$ III tubulin to that of $P C 3$ ) increased also by twofold, indicating an enhancement of neurogenesis in correlation to the expression of $P C 3$ in the neural tube (Fig. 4M).

Analysis of apoptotic cells in adjacent sections of the neural tube, as detected by TUNEL assay, revealed a nonsignificant in- crease (from $9.7 \pm 1.6 \%$ in control $\mathrm{Tg}$ to $12.0 \pm 1.9 \%$ in activated $\mathrm{Tg}$ ) (Fig. $4 E, J, M)$. Consistently, the number of cells per area, as well as the total area of the neural tube, did not change significantly (Fig. 4M). The fact that these latter two parameters remained constant indicated that the total number of $\beta$ III tubulin ${ }^{+}$ neurons increased. In $\mathrm{Tg}$ nestin-rtTA/ TRE-PC3, at E14, a strong increase of $\beta$ III tubulin $^{+}$newborn neurons was also observed throughout the neural tube (hindbrain, midbrain, and forebrain regions) concomitantly with PC3 overexpression (data not shown).

Similarly, the Tg $\beta$ ACT-tTA/TRE-PC3 was examined at E9.5, a stage of development at which the levels of endogenous $P C 3$ are very low in the neural tube. Analysis of transverse sections of the neural tube at the cervical level (Kaufman, 1999, corresponding to his plate $19 \mathrm{a}$, section $\mathrm{i}-\mathrm{k}$ ) indicated that, in the presence of exogenous PC3 expressed in the ventricular and mantle zones, the percentage of $\beta$ III tubulin ${ }^{+} /$total number of cells doubled (from $21.1 \pm 1.3 \%$ in control $\mathrm{Tg}$ to $40.9 \pm$ $3.8 \%$ in activated $\mathrm{Tg}$ ), that apoptosis increased (from $2.7 \pm 0.3 \%$ in control $\mathrm{Tg}$ to $4.5 \pm 0.8 \%$ in activated $\mathrm{Tg}$ ), and that the cell number per area and total area did not present significant changes $(20.7 \pm 1.7$ cells $/ 1000 \mu \mathrm{m}^{2}$ and $1.5 \pm 0.1 \mu \mathrm{m}^{2} \times 10^{5}$ in control Tg vs $18.6 \pm 1.5$ cells $/ 1000 \mu \mathrm{m}^{2}$ and $1.5 \pm 0.1 \mu \mathrm{m}^{2} \times 10^{5}$ in activated $\mathrm{Tg}$ ).

Together, these data indicate that overexpression of PC3 in the neural tube inhibited cell cycle progression and increased the generation of newborn neurons.

\section{PC3 overexpression in the cerebellum arrests proliferation, increases differentiation of GCPs, and induces Math1 expression}

The altered cerebellar phenotype observed at P30 in Tg $\beta A C T-t T A / T R E-P C 3$ (Fig. $2 D, E$ ) prompted us to examine the developmental stages in which active proliferation of GCPs takes place.

We first analyzed cerebella at P1. At this stage, the decreased length of lobules and reduced foliation are already evident in both Tgs $\beta$ ACT-tTA/TRE-PC3 and nestin-rtTA/TRE-PC3 (Fig. $5 A, G, M, S)$.

Expression of endogenous PC3 mRNA in the control animal was detectable in the outer EGL, in the molecular and in the Purkinje cell layers and to a lower extent in the IGL (Fig. $5 H, T$ ). In contrast, expression of the endogenous $P C 3$ protein was more evident in the outer part of the EGL, decreased in the molecular and the Purkinje cell layers, and was barely detectable in the IGL (Fig. 5J, $V$ ). The difference between the expression profiles of $P C 3$ mRNA and protein suggests a translational or posttranslational control. As a whole, $\mathrm{PC} 3$ protein expression was less pro- 
nounced in regions in which postmitotic, premigratory, or postmigratory granule cells were present. This was similar to observations in the neural tube, in which the PC3 protein was expressed mainly in the $\mathrm{VZ}$ and to a lower extent in the surrounding postmitotic mantle zone (Iacopetti et al., 1994, 1999).

Expression of the exogenous PC3 mRNA and protein in cerebellum of the $\mathrm{Tg}$ nestin-rtTA/TRE-PC3 matched the spatial and temporal expression pattern of the endogenous PC3 (Fig. 5O,P). However, the level of the exogenous PC3 protein was higher, particularly in the outer EGL (Fig. $5 P, V)$. In parallel, the endogenous $P C 3$ mRNA appeared to be downregulated by the exogenous $P C 3$, suggesting an autoregulatory loop (Fig. $5 \mathrm{~N}, \mathrm{~T}$ ). A similar pattern was observed in Tg $\beta$ ACT-tTA/TRE-PC3, with the exception that expression of the exogenous PC3 mRNA and protein was stronger and was also very evidently ectopic in the IGL at P1 (Fig. 5C,I,D,J).

In both Tgs, at $\mathrm{P} 1$, a strong decrease of BrdU incorporation and of cyclin D1 expression was evident in the outer EGL (in which cyclin D1 is normally expressed) (Shambaugh et al., 1996) (Fig. 5, compare $E, F$ with $K, L$ and $Q, R$ with $W, X)$. This decrease correlated with the expression of exogenous PC3 in the EGL. However, although the decrease in BrdU labeling was evenly distributed, the localization of $c y$ clin D1 was not uniform in all folia and lobules, which raised the possibility that other members of the cyclin D family could be involved. As judged by Western blot analysis of the whole cerebellum, a barely detectable decrease of cyclin D2 expression was observed, whereas cyclin D1 was clearly reduced (10 and 40\%, respectively, by densitometry). No change was observed for cyclin D3 and for $N$ $m y c$, known to exert a positive control on cyclin D2 expression (Knoepfler et al., 2002) (supplemental Fig. 1; available at www.jneurosci.org).

Unexpectedly, an increase of NF160 $\mathrm{kDa}$ staining was observed in the whole cerebellum, particularly in the IGL and in the molecular layer, whose thickness was significantly increased (Fig. 6A,F, $K, P$ ). Moreover, in some lobules, NF-positive cells were detectable in the inner and even in the outer EGL (Fig. $6 A, L$, arrows), indicating that GCPs differentiated in an area in which they are normally still proliferating.

To further analyze the differentiation of GCPs at P1, we studied the expression of the basic helix-loop-helix transcription factor Math1, which is normally expressed in GCPs (Akazawa et al., 1995; Ben-Arie et al., 1997, 2000; Helms et al., 2001). In both Tgs, a marked increase in Math1 expression was identified in the outer EGL (Fig. 6B, C and $L, M$ ) compared with the control (Fig. 6G, $H$ and $Q, R)$. Math1 was also highly expressed ectopically in the IGL

\section{Tg nestin-rtTA/TRE-PC3 E12.5}
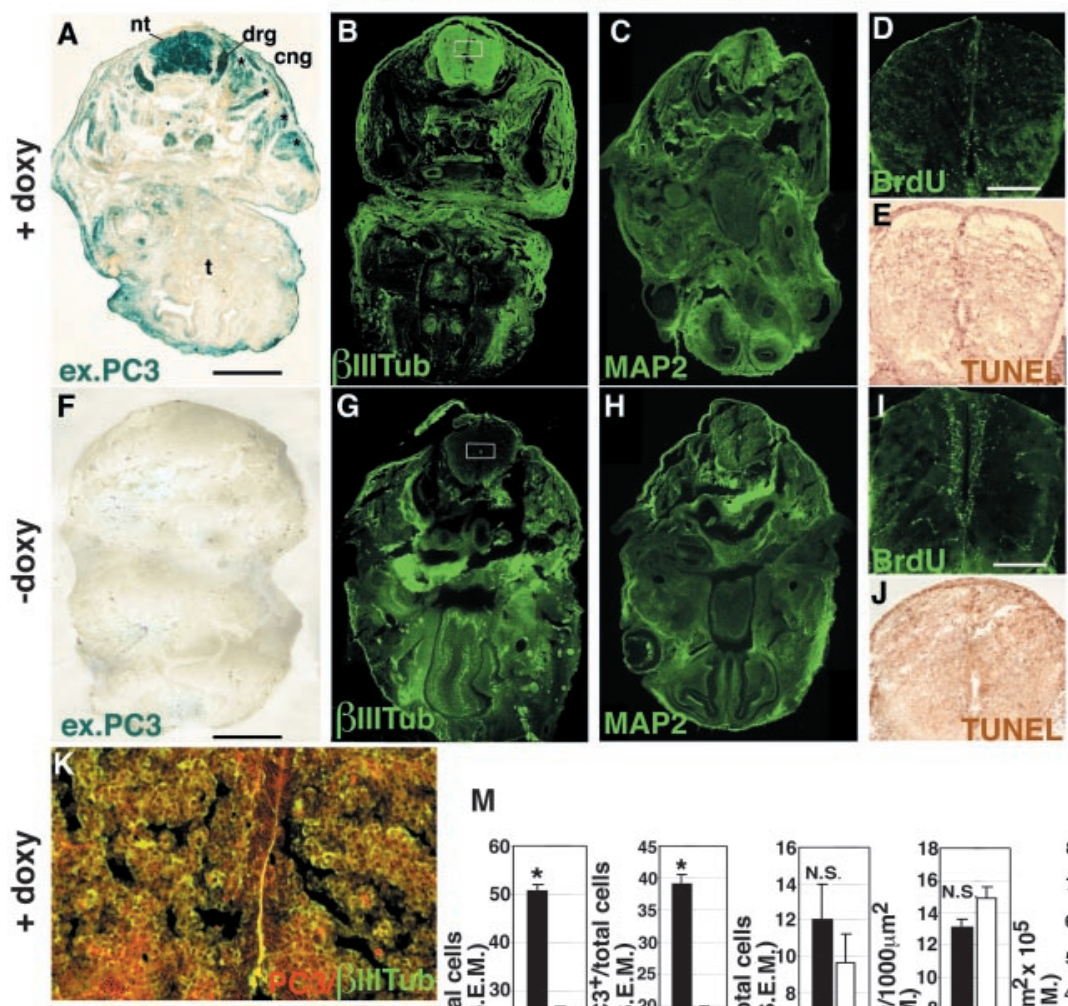

M
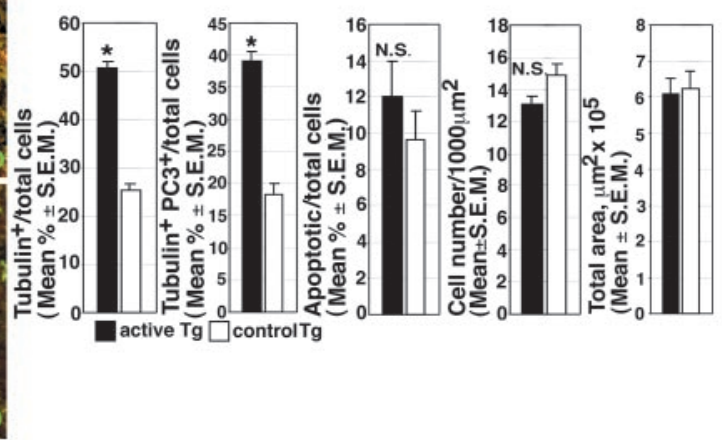

Figure 4. Increase of postmitotic newborn neurons after overexpression of $P(3$ in the neural tube at $E 12.5$. Transverse sections nous $P C 3(A, F)$, the indicated neuronal markers $(B, C, G, H)$, BrdU incorporation $(D, I)$, and apoptosis by the TUNEL assay $(E, J)$. in an adjacent section double labeled for $P C 3 / \beta \mathrm{III}$ tubulin. Activation of the $P(3$ transgene $(K)$ is associated with an increase of $\beta$ III tubulin ${ }^{+}$cells, in which most are yellow-green (unlike in the control, $L$ ), indicating coexpression of $P(3 . M$, Quantitative analysis of differentiation (percentage ratio of $\beta \mathrm{III}$ tubulin $^{+}$neurons to the total number of cells and percentage ratio of $\beta \mathrm{III}$ tubulin ${ }^{+} P\left(3^{+}\right.$neurons to the total number of cells), apoptosis (percentage ratio of TUNEL ${ }^{+}$neurons to the total number of (ells), total cell number per area, and total area of the neural tube. The total number of cells was obtained by counting nucle stained by Hoechst 33258. Values were calculated within the neural tube area from transverse sections localized and spaced as indicated above ( 3 transversal adjacent sections for each of 3 mice, for a total of 9 sections for either the activated or the control Tg; the fields analyzed covered the entire neural tube area). ${ }^{*} p<0.001$ versus control (Student's $t$ test). nt, Neural tube; drg, dorsal root ganglia; cng, cranial nerve ganglia, indicated by a black asterisk; t, tongue. Scale bars: A, F, $1100 \mu \mathrm{m} ; D, I, 240 \mu \mathrm{m}$.

of Tg $\beta$ ACT-tTA/TRE-PC3 and, to a lower extent, of Tg nestinrtTA/TRE-PC3 (Fig. $6 B, C, L, M$ ) (see Fig. $8 D, D^{\prime}$ ), in agreement with the ectopic expression of PC3 protein in this area. Ectopic expression of Math1 protein (and mRNA, data not shown) in the IGL occurred mainly in granule cells but was observed to some extent also in Purkinje neurons (labeled by calbindin) (Fig. 6B, C). Moreover, Purkinje neurons showed abnormal clustering, rather than a coordinated layer, in the Tg $\beta$ ACT-tTA/TRE- $P C 3$ and, to a lower extent, in the Tg nestin-rtTA/TRE-PC3 (Figs. 5D, J, $P, V, 6 B, G$ ). However, this alteration was not directly correlated with the expression of PC3 in these cells. In fact, PC3 was weakly detectable in Purkinje neurons only in the Tg $\beta$ ACT-tTA/TRE-PC3 (Fig. 5D).

Changes were observed also in the expression of NeuroD, 

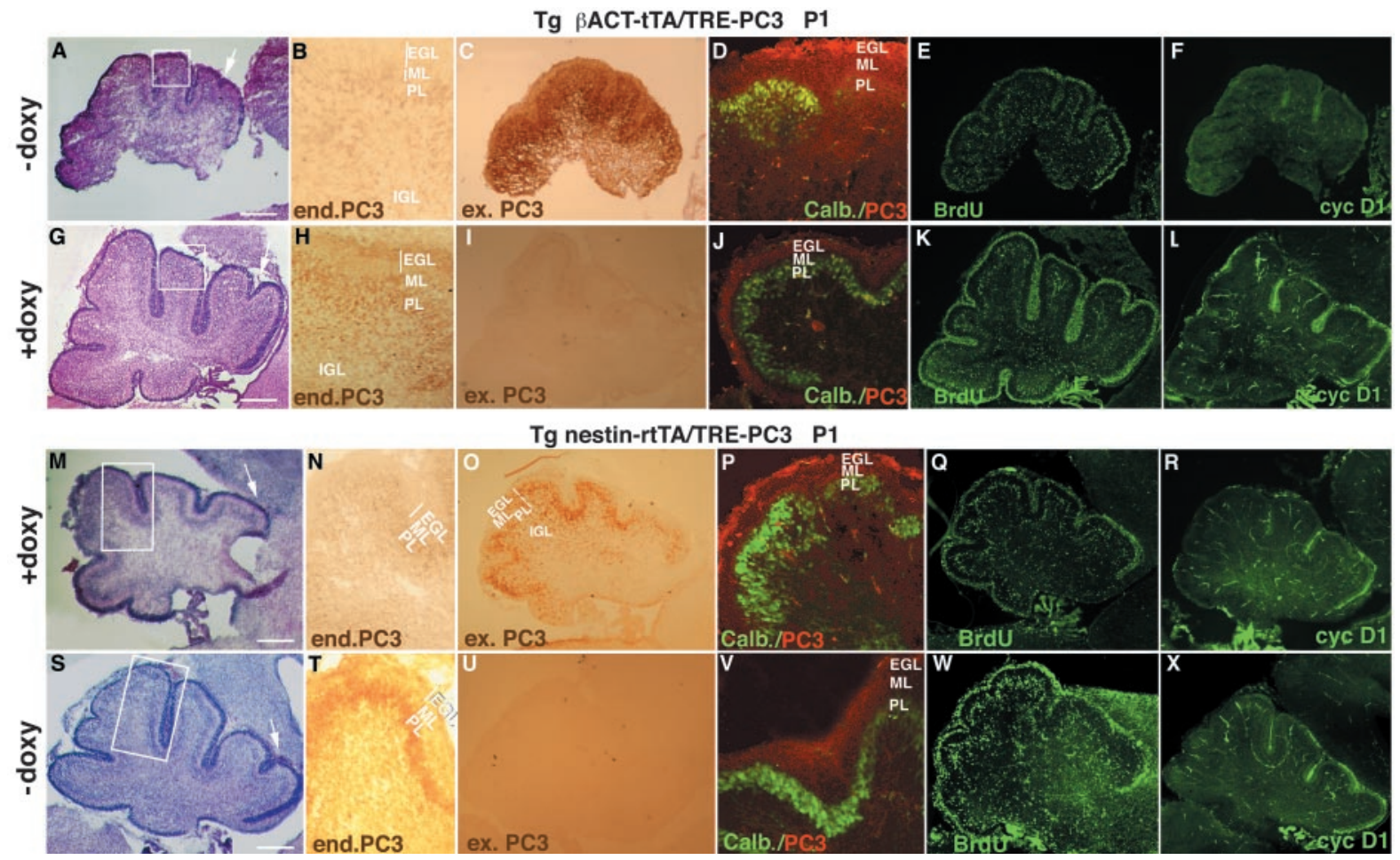

Figure 5. Overexpression of $P C 3$ inhibits the proliferation and the cyclin D1 expression of GCPs in cerebellum at $P 1$, in $\operatorname{Tg} \beta A C T-\mathrm{tTA} / \mathrm{TRE}-P C 3(A-L)$ and in Tg nestin-rtTA/TRE-PC3 (M-X). $A, G, M$, $S$, Hematoxylin and eosin staining indicates reduced size of lobules. - doxy corresponds to active $\operatorname{Tg} \beta$ ACT-tTA/TRE-PC3, whereas + doxy corresponds to active Tg nestin-rtTA/TRE-PC3. Endogenous (end.; $B, H, N, T$ ) and exogenous (ex.; $C, I, O, U) P C 3$ mRNA expression is shown as detected by ISH using specific biotin-labeled probes (boxes in $A, G, M, S)$. ML, Molecular layer; PL, Purkinje layer; Calb., calbindin. $D, J, P, V$, Confocal microscopy analysis of folia indicated by arrows in $A, G, M$, and $S$ for $P C 3$ protein expression, which increases in the outer EGL and, to a lower extent, in the IGL, and for calbindin (which marks Purkinje neurons). The markers analyzed are indicated. Purkinje neurons are organized in clusters rather than in layers as in controls. $E, K, Q, W, B r d U$ incorporation is reduced; $F, L, R, X$, cyclin D1 expression decreases when transgenes are active. Scale bars, $140 \mu \mathrm{m}$. Adjacent sagittal sections were spaced $10 \mu \mathrm{m}$.

which labels the immediately postmitotic granule cells in the inner EGL and in the molecular layer, thus before and at the onset of their migration (Miyata et al., 1999). These migratory NeuroD-positive granule cells were reduced in number in the molecular and Purkinje layers and appeared to accumulate in the inner and also in the outer EGL in both $\beta$ ACT-tTA/TRE-PC3 and nestin-rtTA/TRE- $P C 3$ Tgs (Fig. $6 D, I, N, S$ ), suggesting that granule cell migration was affected. Frequently, NeuroD-positive granule cells in the outer EGL and molecular layer also expressed NF160, indicating an accelerated differentiation (Fig. $6 D, N$ ).

Furthermore, an increase was observed in the number of apoptotic nuclei in the outer one-third of the EGL (three to four GCPs layers), as detected by TUNEL assay, in both Tgs at P1, in correlation with the maximal expression of exogenous PC3 protein (Fig. 6E,J,O,T).

We then analyzed cerebella at P5 (Figs. 7, 8). At this stage, in $\operatorname{Tg} \beta$ ACT-tTA/TRE- $P C 3$, all of the modifications observed in the P1 cerebellum were still detectable, namely, reduced cerebellar size (Fig. $7 A, D$ ), decrease of BrdU incorporation and cyclin D1 expression (Fig. 8 and data not shown), increase of NF160 staining in the IGL (Fig. 7C,F), and increase of Math1 expression in the EGL and IGL (Fig. 7G,J), concomitantly with expression of exogenous PC3 mRNA (Fig. $7 B, E$ ). The migration of NeuroDpositive granule cells was still reduced, but the normal localization of Purkinje cells was almost restored (Fig. $7 H, K, G, J$ ). In turn, the radial pattern and position of the Bergmann glia, detected by GFAP (Levitt and Rakic, 1980), was severely disorganized at P5 in the $\beta$ ACT-tTA/TRE-PC3 (Fig. $7 I, L$ ). Remarkably, however, none of these changes was detectable at P5 in the cerebellum of Tg nestin-rtTA/TRE-PC3, which regained normal morphology (Fig. 7M-T). This correlated with the complete downregulation of exogenous $P C 3$ expression, attributable to the physiological inactivation of the nestin promoter at P5 (Fig. $7 N, P)$.

In summary, in both Tgs, the $\mathrm{PC} 3$ protein was overexpressed in the EGL and, ectopically, in the IGL. This was followed by a decrease in EGL proliferation, as was evident by reduced cyclin D1 levels and BrdU incorporation. Moreover, a significant increase in Math1 expression was seen in the EGL, and ectopically in the IGL, with a strong enhancement of granule cells differentiation, as judged by NF and NeuroD levels. The ectopic induction of Math1 correlated with the ectopic expression of PC3 in the IGL and with the disorganization of the Purkinje cell layer. Together, these observations point to an effect of $P C 3$ on the proliferation and differentiation of GCPs as the basis for the cerebellar phenotype.

Cell cycle inhibition, Math1, and NF induction and apoptosis: quantitative analysis in cerebellum

To quantify the changes observed, the Tg mice, $\beta$ ACT-tTA/TRE$P C 3$ and nestin-rtTA/TRE- $P C 3$, activated since fertilization as described above, were exposed to BrdU for $1.5 \mathrm{hr}$, and the BrdULI was analyzed in the whole EGL at P1 and P5 (Fig. $8 A, A^{\prime}$ ).

BrdULI was significantly reduced by expression of $P C 3$ in $\mathrm{Tg}$ $\beta$ ACT-tTA/TRE- $P C 3$ of 40.5 and $38 \%$ at $P 1$ and $P 5$, respectively, whereas BrdULI in Tg nestin-rtTA/TRE-PC3 decreased significantly (37.1\%) only at P1, being restored to control values at P5 in correlation with the disappearance of exogenous $P C 3$ expression (Figs. $7 N, P, 8 A, A^{\prime}$ ). Measurements of BrdULI were not influenced by apoptotic GCPs, whose nuclei with condensed and frag- 
Tg BACT-tTA/TRE-PC3 P1
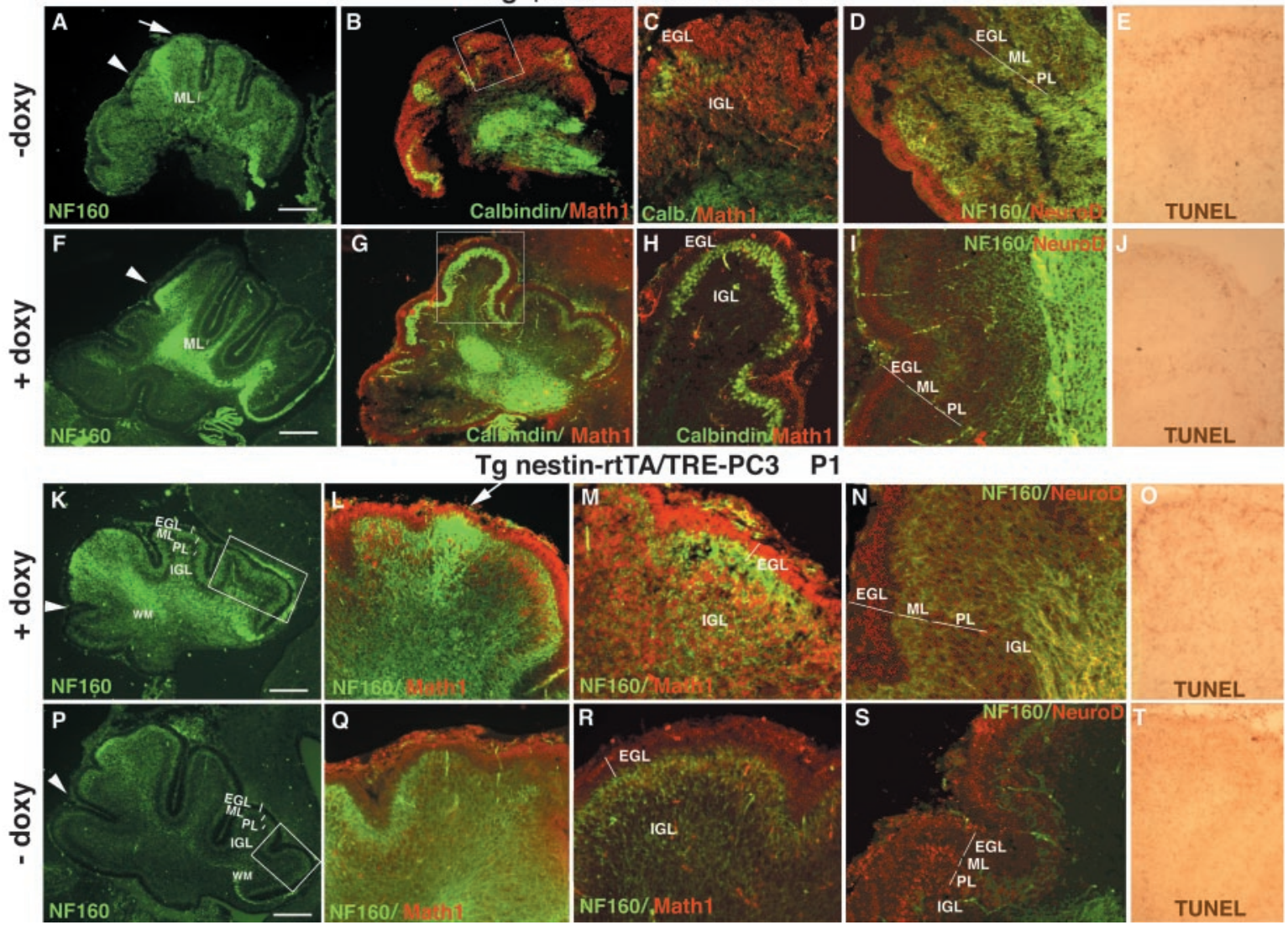

Figure 6. Overexpression of $P C 3$ strongly increases the differentiation of granule cells and the expression of Math1 in cerebellum at P1, in Tg $\beta A C T-$ tTA/TRE-PC3 ( $A-J)$ and in Tg nestin-rtTA/ TRE-PC3 $(K-T) . A, F, K, P$, Increase of NF160 expression in cerebella of mice with active transgene. The width of the molecular layer (ML) is increased, and NF ${ }^{+}$cells are present also in outer EGL (arrow in $A$ ). $B, G, L, Q$, Math 1 expression increases in EGL and also in IGL. The regions analyzed in $L$ and $Q$ are defined by boxes in $K$ and $P$. The arrow in $L$ indicates the presence of $\mathrm{NF}^{+}$cells within the inner EGL in the activated Tg, never observed in control mice, as also shown by confocal microscopy in $M . C, H, M, R$, Confocal microscopy magnification from adjacent sections (the region analyzed in Cand $H$ is defined by boxes in $B$ and $G$ ). $D, I, N, S$, Analysis of NeuroD/NF160 expression by confocal microscopy in adjacent sections (in regions indicated by arrowheads in $A, F, K, P)$, showing increase of NeuroD ${ }^{+}$cells in the outer EGL and decrease in the ML-IGL. E, J, O, T, Representative TUNEL analyses of EGL fields. WM, White matter; PL, plexiform layer. Scale bars, $160 \mu \mathrm{m}$. Adjacent sagittal sections were spaced $10 \mu \mathrm{m}$.

mented chromatin were not counted (Oberhammer et al., 1992). Cyclin D1 expression was downregulated in parallel with the reduction of BrdULI (Fig. $8 B, B^{\prime}$ ).

The extent of granule cell differentiation was analyzed by measuring the total IGL area positive for NF160 staining. This showed an increase of $>2.5$-fold in Tg $\beta$ ACT-tTA/TRE- $P C 3$ and in Tg nestin-rtTA/TRE- $P C 3$ at $\mathrm{P} 1$, whereas at P5, only the former $\mathrm{Tg}$ showed a significant increment (Fig. $8 C, C^{\prime}$ ). A large increase was also observed in the percentage of $\mathrm{Math}^{+} /$total cells in the IGL, up to sevenfold in Tg $\beta$ ACT-tTA/TRE-PC3 and more than threefold in Tg nestin-rtTA/TRE-PC3 at P1 (Fig. $8 D, D^{\prime}$ ). The increases in NF160 and Math1 expression were highly proportional, suggesting a correlation between them.

As shown in Figure $8, E$ and $E^{\prime}$, TUNEL assay indicated that apoptosis was significantly increased in the EGL of Tg $\beta$ ACTtTA/TRE-PC3, whereas in the IGL and in Tg nestin-rtTA/TRE$P C 3$, the increase was slight and nonsignificant. The total number of cells within the EGL (cell number $/ 1 \times 10^{3} \mu \mathrm{m}^{2}$ ), which represents a measure of the GCP pool turnover (see Discussion), did not change significantly in both Tgs with active expression of $P C 3$ (Fig. $8 F, F^{\prime}$ ). The absence of evident changes in cell number was consistent with the unchanged EGL thickness (Fig. $5 A, G, M, S)$.
PC3 acts upstream of Math1 and controls its transcription

Having found that transgenic PC3 expression increased the expression of Math1, we sought to test whether Mathl is a target of $P C 3$ action by an independent approach. We therefore generated primary cultures of postmitotic cerebellar granule cells from P8 rats, which do not normally express Mathl, grew the cultures for an additional $5 \mathrm{~d}$ and transduced them with a recombinant $P C 3$ expressing adenovirus (Adeno-PC3) $24 \mathrm{hr}$ before harvesting. In control cultures infected with Adeno- $\beta$-gal, Math 1 mRNA was undetectable (Fig. 9A), as expected (Akazawa et al., 1995; BenArie et al., 2000). In contrast, infection with Adeno- $P C 3$ caused a strong reactivation of Math1 mRNA (Fig. 9A). Furthermore, the expression levels of the transcription factors Zic1 (Aruga et al., 1998 ) and to a lower extent Zipro1 (Yang et al., 1999), which are expressed in vivo in both the EGL and IGL, were also induced by PC3. Similarly, the level of NeuroD mRNA, whose expression is needed for differentiation and is maintained in mature granule cells (Lee, 1996; Miyata et al., 1999), was also slightly increased (Fig. 9A).

Because the level of Math1 increased after infection by Adeno$P C 3$, we evaluated whether this effect was common to other cell cycle inhibitory genes. We chose the cyclin-dependent kinase inhibitors $p 21$ and $p 27$, known to be expressed in cerebellar granule 


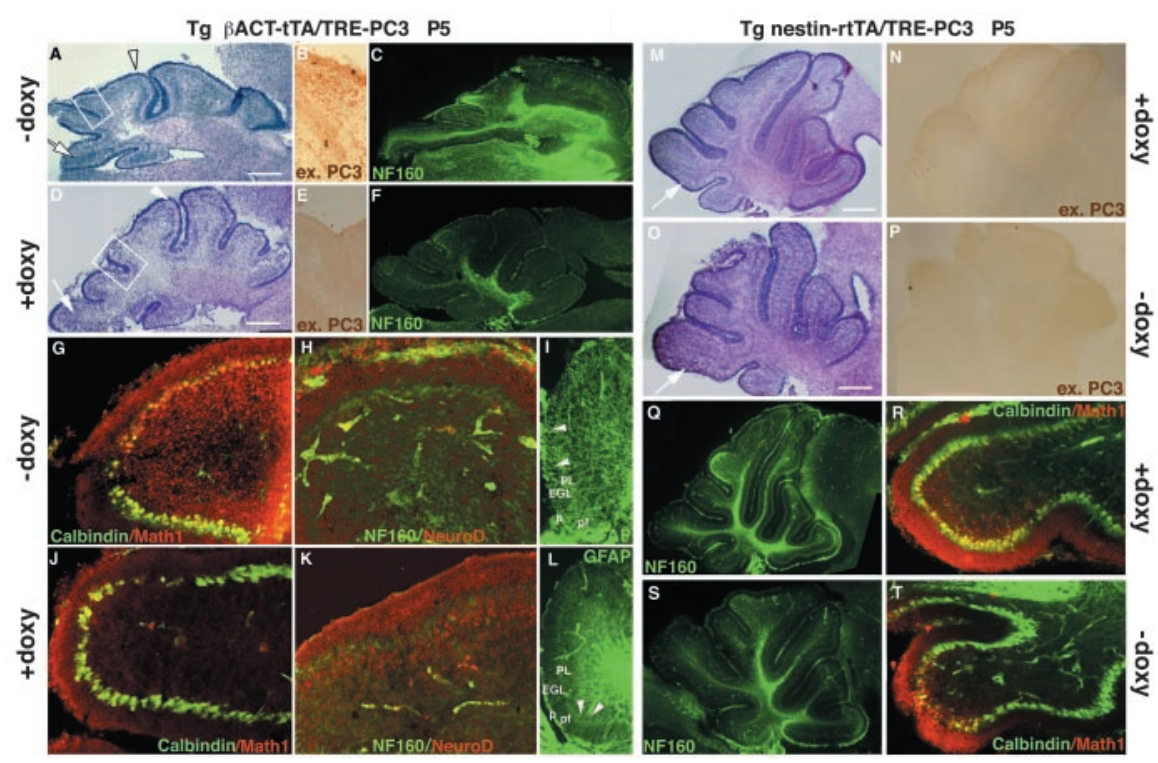

Figure 7. The continued increase at $P 5$ of granule cell differentiation and of Math1 expression is dependent on the presence of exogenous $P C 3$. $A-L$, Continued overexpression of $P C 3$ in the $E G L$ and molecular layer of $\mathrm{Tg} \beta A C T-\mathrm{tTA} / \mathrm{TRE}-P C 3$ at $P 5$ maintains the increase of granule cell differentiation (as shown in $C, F$ ) and of Math1 expression (as shown in $G, J$ ), as well as the arrest of proliferation in GCPs (for quantitative analyses of BrdULI and of NF and Math1 expression, see Fig. $8 A-F$ ). The various markers and Tg treatments are as in Figures 5 and 6. Boxes in $A$ and $D$ mark the region analyzed by ISH for exogenous (ex.) $P C 3 \mathrm{mRNA}$ in $B$ and $E$; arrows mark $G$ and $J$ fields, and arrowheads indicate the region analyzed by confocal microscopy in $H$ and $K . I, L$, The radial organization of parallel fibers in the EGL, evident in P5 control mice (+ doxy), is absent in $\mathrm{Tg} \beta A C T$-tTA/TRE-PC3, and Bergmann glial cells (representatively indicated by arrowheads) are misplaced throughout the EGL. p, Pia; pf, parallel fibers. M-T, Physiological arrest of nestin promoter-driven expression of exogenous $P C 3$ in $\mathrm{Tg}$ nestin-rtTA/TRE-PC3 at P5 is associated with the disappearance of the cerebellar phenotype. Arrows in $M$ and 0 mark the lobe analyzed in $R$ and $T$ for Math1 expression. Scale bars: $A, D, 190 \mu \mathrm{m} ; M, 0,200 \mu \mathrm{m}$. Adjacent sagittal sections were spaced $10 \mu \mathrm{m}$.

precursors in the EGL during the period P0-P9 (Shambaugh et al., 2000). No induction of Math1 was detectable after infection of primary cultures of cerebellar granule cells with recombinant p21 or p27 adenoviruses (Adeno- $p 21$ and Adeno- $p 27$ ), indicating that the induction of Math1 was a specific function of PC3 (supplemental Fig. 2).

Next, we asked whether PC3 could activate Math1 transcription via its promoter elements. For this, we generated the construct pGL3-Math1-pr/-1200, which included the Math1 promoter region upstream to the luciferase reporter gene. This construct was cotransfected with PC3 into primary cultures of cerebellar granule cells or into PC12 cells differentiated into sympathetic neurons by NGF treatment. Indeed, Math1 promoter activity was significantly induced by PC3 transfected in rat P2 (and P8; data not shown) granule cell cultures, as well as in sympathetic neurons (Fig. 9B).

In contrast, when tested in cerebellar granule cells, ectopic PC3 was unable to stimulate a luciferase reporter placed under the control of the Math1 enhancer (construct pGL3-Math1-enh) (Fig. 9B), which is responsible for the positive autoregulation of Math1 (Helms et al., 2000). This suggested that PC3 acts through DNA motif(s) within the Math1 gene promoter region and not through its enhancer (Fig. 9B).

Furthermore, cerebella of E14 Math1 $1^{-/}$mice, lacking the entire coding region of Math1, showed normal levels of PC3 (Tis21) mRNA, indicating that no feedback mechanism was exerted by Math1 on the transcription of endogenous PC3 and confirming that $P C 3$ acts upstream of Math1 (Fig. 9C).

As a preliminary assessment of the existence of a physiological interaction between Math1 and PC3, we also performed an ISH analysis of the expression of Math1 and PC3 mRNAs in wild-type mice. Their localization throughout the cerebellar development, from E14 to P30, was closely overlapping (supplemental Fig. 3).

\section{Discussion}

Overexpression of $P C 3$ in neuronal tissues during embryonic and postnatal periods leads to a surprising increase of neuronal differentiation throughout the neural tube and in the cerebellum, as indicated by the increase of $\beta$ III tubulin or NF-positive cells. This effect was associated with reduced BrdU incorporation and overlapped with the regions of $P C 3$ overexpression, which corresponded quite faithfully to those in which endogenous PC3 was expressed. In both binary transgenics used ( $\beta$ ACT-tTA/TRE-PC3 and nestin-rtTA/ TRE-PC3), expression of PC3 in the nervous system was limited to proliferating and differentiating neuronal precursors. In the neural tube, the occurrence of neurogenesis and expression of PC3 were directly correlated, because $\beta$ III tubulin ${ }^{+}$ neurons were also positive for transgenic PC3 mRNA and protein. A key question arising from these observations was whether the inhibition of cell cycle progression exerted by $P C 3$, forcing the neuroepithelial cell to exit from the cell cycle, is in itself sufficient to cause the increased differentiation that we observed. An indication that the two PC3-mediated effects, although coordinated, rely on different mechanisms, came from the analysis of the cerebellar phenotype.

\section{The $G_{1}$ to $S$ phase transition is inhibited in cerebellar GCPs expressing $P C 3$}

In the cerebella of both binary transgenic animals analyzed, overexpression of $P C 3$ correlated with a significant reduction of BrdU incorporation and of cyclin D1 expression, as well as with a marked increase of Math1 and NF160 kDa expression and with apoptosis. The highest expression of exogenous PC3 occurred in the outer EGL, where it was accompanied by massive differentiation of GCPs, and in the IGL, where it was accompanied by ectopic induction of Math1 that is not normally expressed in this area. How can these events be correlated?

Induction of PC3 in the outer EGL of both binary transgenic models inhibited the cell cycle progression of GCPs, as indicated by the reduction of BrdU incorporation, coherently with the observed downregulation of cyclin D1. The decrease of the BrdU labeling index in the EGL could reflect an increase in the fraction of cells in quiescence (Q; i.e., GCPs that became postmitotic), longer duration of the $\mathrm{G}_{1}$ phase $\left(\mathrm{T}_{\mathrm{G1}}\right)$ or an increase of the duration of the cycle $\left(\mathrm{T}_{\mathrm{C}}\right)$. Additional analyses will be necessary to define these possibilities. At any rate, a reduction of cyclin D1 expression, as was observed, invariably leads to an impairment of CDK4 (cyclin-dependent kinase 4) activity and thus to an inhibition of the $G_{1}$ to $S$ phase transition (Baldin et al., 1993). Moreover, the primary effect of $P C 3$, as identified by our previous in vitro studies on neuronal and non-neuronal cells, is a selective impairment of $G_{1}$ to $S$ phase progression through inhibition of 
cyclin D1 transcription (Montagnoli et al., 1996; Guardavaccaro et al., 2000; Tirone, 2001). Cyclin D2, which has been shown to play a role in cerebellar development (Ciemerych et al., 2002), displayed only weak reduction, if any, by PC3. This points to cyclin D1, among D-type cyclins, as the main target of PC3 in cerebellum.

Combined influence of PC3 on proliferation, differentiation, and migration of GCPs underlie the cerebellar phenotype

Overexpression of PC3 in the cerebellum at $\mathrm{P} 1$ correlated with a widespread increase of the differentiation of GCPs, with fully differentiated granule cells detected even within the EGL, as shown by NF expression. This indicated that the postmitotic state was attained with a higher frequency and that differentiation occurred also before migration.

A strong increase in the generation of postmitotic cells would lead to a decrease of the active pool of proliferating precursors (given that GCPs, after entering Q, migrate outside the EGL within 24-48 hr) (Rakic, 1971), as would a lengthening of the $G_{1}$ phase. Indeed, we observed an accumulation of postmitotic NeuroDpositive granule cells in the whole EGL. This may be explained by an excess of differentiating granule cells entering $Q$ and/or by impaired radial migration, as suggested by the disorganization of the Bergmann glia, which guide granule cell migration (Rakic, 1971; Hatten, 1999). Reduced migration, concomitant with the increase of $\mathrm{Q}$ and $\mathrm{T}_{\mathrm{G} 1}$, might thus account for the observation that the number of EGL cells remained constant.

It is known that the differentiation of granule cells influences the development of Purkinje neurons (Morrison and Mason, 1998), which in turn control Bergmann glia differentiation and the proliferation and migration of EGL granule precursors (Zecevic and Rakic, 1976; Fisher et al., 1993; Sotelo et al., 1994; Dahmane and Ruiz i Altaba, 1999; Kenney and Rowitch, 2000; Komuro et al., 2001). However, it seems unlikely that the disruption observed in the organization of Purkinje cells and of Bergmann glia had a causal effect on the cerebellar phenotype given that, in Tg nestin-rtTA/TRE-PC3 (in which the PC3 protein is undetectable in Purkinje cells at P1), a significant reduction of cerebellar size and granule cell migration occurred in the presence of a mild disorganization of the Purkinje cell layer. This was notably completely reversed at $\mathrm{P} 5$, when the overexpression of PC3 in granule cells had ceased. Thus, the altered pattern of Purkinje cells and Bergmann glia (clearly evident only in Tg $\beta$ ACTtTA/TRE-PC3 in which PC3 is ectopically expressed in Purkinje cells) could have been an additional factor influencing the cerebellar phenotype, partly secondary to the effects of $P C 3$ on granule cells.

Moreover, given that the appearance of the Bergmann glia is not dramatically changed, an alternative interpretation should be considered, which can account for the unchanged EGL thickness without involving granule cell migration. Because Purkinje cells are disorganized and fewer granule cells are generated, the overall volume of the cerebellum is reduced. Thus, if volume and rate of neurogenesis are reasonably matched, then the thickness of the EGL may not be changed, although its area over the surface of the cerebellum is reduced. If, in contrast, we take into account a migration defect in the newly generated granule neurons, it remains to be seen whether this reflects an influence of radial glia or an intrinsic motility problem in the granule cells themselves, whose differentiation has been anticipated.

As a whole, the observations above suggest that the reduced cerebellar size in both bitransgenic models resulted mainly from reduced proliferation of GCPs in the postnatal mice and from the associated increase of the fraction of GCPs entering Q and differentiating. On the other hand, increased apoptosis of GCPs in the outer EGL might have contributed to the reduced cerebellar size, decreasing the number of GCPs. The increased apoptosis observed appears contradictory with previous data, indicating that $P C 3$ protects postmitotic neurons from death caused by deprivation of trophic factors in vitro (Corrente et al., 2002). Notably, apoptosis increased significantly only in the EGL of Tg $\beta$ ACTtTA/TRE-PC3, in which the expression of $P C 3$ in GCPs was high. We suggest that, in the rapidly dividing GCPs undergoing clonal expansion (Hatten, 1999), a strong inhibition of cell cycle progression represents a conflicting signal that leads to apoptosis, as shown in other systems (Tiemann and Hinds, 1998). The modest increase of apoptosis in the neural tube, or in the IGL of transgenic mice, is consistent with the idea that the excess number of differentiating neuronal stem cells is controlled by programmed 


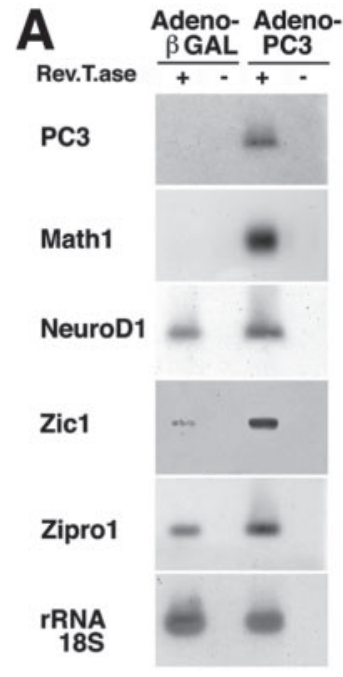

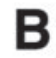

$3 \stackrel{\text { reporten }}{2}$
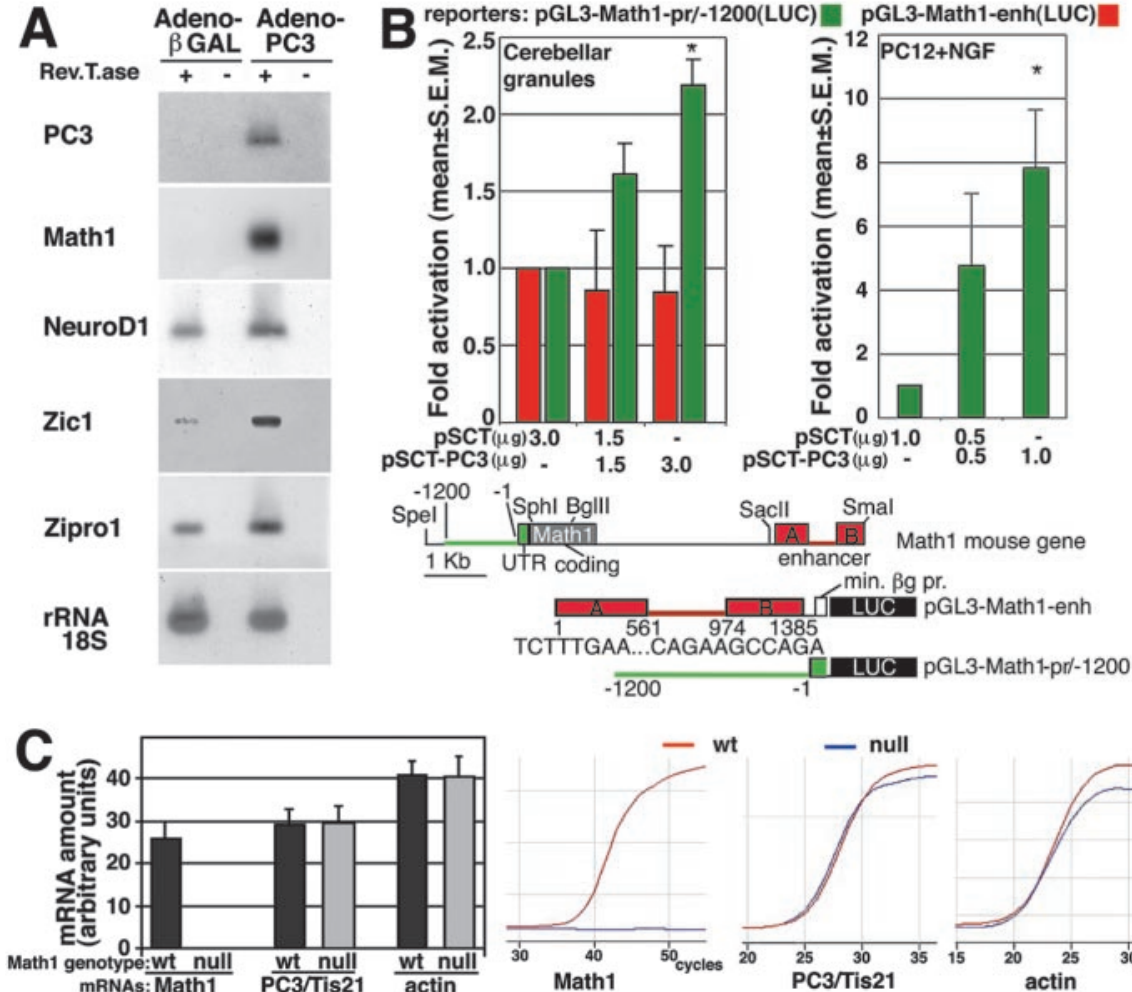

D

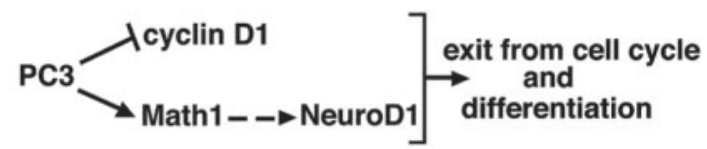

Figure 9. Dissection of the molecular pathway of Math 1 induction by $P C 3$. A, Recombinant adenovirus encoding $P C 3$ (Adeno$P(3)$ induces Math1 mRNA in primary cultures of cerebellar granule cells, as indicated by semiquantitative RT-PCR analysis, although no expression is seen in $\beta$-gal adenovirus-transduced cells. mRNAs of other proneural genes are analyzed, as indicated. Rev.T.ase $(+/-)$, Amplifications with or without reverse transcriptase as controls for genomic DNA contamination. One representative experiment out of four is shown. $B, \mathrm{PC} 3$, ectopically expressed by transfection in primary cultures of cerebellar granule cells from P2 rats, and in chromaffin PC12 cells differentiated into sympathetic neurons (after $48 \mathrm{hr}$ treatment with NGF, 50 $\mathrm{ng} / \mathrm{ml}$ ), stimulates the activity of the Math 1 promoter region. This comprised $1200 \mathrm{nt} 5^{\prime}$ to the putative transcription start (Akazawa et al., 1995), placed upstream to a luciferase reporter (construct pGL3-Math1-pr/-1200, indicated by green bars in the luciferase assays. The green line in the schematic representation of the Math1 mouse gene and of the constructs shows the promoter region analyzed). Math1 gene enhancer sequence (Helms et al., 2000) was not transcriptionally stimulated by $P C 3$ [construct pGL3-Math1-enh (Helms et al., 2001, corresponding to their construct \#9)] (see Materials and Methods) (indicated by red bars in the luciferase assays; the red boxes in the scheme below show the enhancer region analyzed). Min. $\beta \mathrm{g}$ pr., Minimal $\beta$ globin promoter. In PC12 cells, NGF treatment was started immediately after transfection of pSCT-PC3 or pSCT empty expression vector (Corrente et al., 2002). The average \pm SEM fold increase in luciferase activity of four experiments is shown for each type of cells relative to the level of control samples. Luciferase activities were measured in luciferase units per microgram of protein normalized to the activity of the coreporter pRL-TK (containing the herpes simplex virus thymidine kinase promoter region upstream of the Renilla luciferase gene; Promega) present in each extract, as a measure of the efficiency of transfection. The activity of Math1 promoter and enhancer (constructs pGL3-Math1/-1200 and pGL3-Math1-enh) resulted severalfold above the background, represented by the activity of the empty pGL 3 basic vector. The expression of transfected $P C 3$ was verified by Western blot (data not shown). ${ }^{*} p<0.05$ versus control (Student's $t$ test on raw data). $C$, In mice with ablation of Math 1 , the levels of $P C 3 /$ Tis21 (Tis21, i.e., the mouse homolog of $P(3)$ were not affected, confirming that $P C 3$ acts upstream. Real-time RT-PCRanalysis of $P\left(3 /\right.$ Tis 21 and Math $1 \mathrm{mRNA}$ levels in Math $1^{-1-}$ and wild-type E14 cerebella: the average \pm SEM values are shown from four replicates. D, A schematic model proposed for $P C 3$ activity in cerebellar granule cells (see Discussion). Math 1 is depicted upstream of NeuroD1, consistent with previous findings (Miyata et al., 1999).

cell death, a physiological feature of neuronal development (for review, see Sommer and Rao, 2002).

\section{PC3-dependent induction of Math1 and cell cycle arrest are coordinated but dissociable events}

The effects of $P C 3$ on cerebellar development raised the question as to whether GCPs in EGL become postmitotic and differentiate merely as the result of the cell cycle exit triggered by PC3.

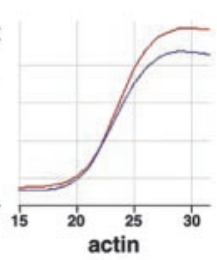

In neural crest-derived pheochromocytoma cells, expression of ectopic $P C 3$ led to inhibition of cell cycle in $\mathrm{G}_{1}$, but this was not accompanied by differentiation. Rather, PC3 strongly enhanced the NGFinduced differentiation of these cells (Corrente et al., 2002; el-Ghissassi et al., 2002; F. Tirone, unpublished data).

In contrast, in cerebellar granule cells, PC3 appears to have an instructive role in GCP differentiation, because we showed that it activates the expression of Math1, both in vivo and in vitro. Although apparently not involved in the process of specification of GCPs, Math1 is essential for their differentiation, as demonstrated by experiments of ablation in vivo and in vitro (Ben-Arie et al., 1997; Gazit et al., 2004). Consistently, its overexpression in vivo has been shown to drive the expression of early differentiation markers in postmitotic granule cells, confirming a role of Math1 in their differentiation (Helms et al., 2001). Thus, the increased differentiation of granule cells associated with the expression of $P C 3$ can be plausibly dependent on the induction of Math1 by PC3. Furthermore, we showed that $P C 3$ can induce the transcription of Math1 by activating the Math1 gene promoter. Such an effect is consistent with the known activity of PC3 as a transcriptional regulator. In fact, PC3, which is in itself devoid of transactivating function and does not directly bind DNA, has been shown to associate with subunits of the multiprotein transcriptional complex CCR4-Not (Rouault et al., 1998; our unpublished data).

The expressions of exogenous and endogenous PC3 mRNA in Tg nestin-rtTA/ TRE-PC3 at P1 overlap closely, being maximal in proliferating GCPs of the EGL and rapidly decreasing in deeper regions. In $\mathrm{Tg}$ $\beta$ ACT-tTA/TRE- $P C 3$, with a more evident phenotype, exogenous PC3 levels remained high also in mature IGL granule cells. It can thus be assumed that the cerebellar phenotype observed was obtained through various degrees of enhancement of a physiological process, by increased expression of $P C 3$ in granule cell precursors.

We therefore hypothesize that $P C 3$ can physiologically exert a dual action, by promoting the $\mathrm{G}_{1}$ arrest of GCPs in the EGL through inhibition of cyclin D1 and, in parallel, by stimulating their differentiation through induction of Math1. As a result, GCPs undergo terminal cell cycle exit to quiescence (Fig. 9D). In this model, Math1 may be ineffective, or less effective as a neural inducer, in the absence of a growth arrest signal. Interestingly, it has been observed in Xenopus that the ability of ectopic Xath5 (amphibian ortholog of Math5, a close paralog of Math1) to drive retinal precursors toward retinal ganglion cell fate is enhanced by forcing cell cycle exit via cotransfec- 
tion of p27 (Ohnuma et al., 2002). On the other hand, in Math1 null mice, which fail to develop the EGL, expression of $P C 3$ in the cerebellar primordium is unaffected, implying that $P C 3$ in itself is not sufficient to induce GCP differentiation. Thus, PC3 may coordinately induce growth arrest and the differentiation activity of Math1 in GCPs. The idea that the induction of Math1 by PC3 may occur physiologically is clearly compatible with the temporal and spatial coincidence of the expression patterns of Math1 and PC3 mRNAs in the developing cerebellum (analyzed at E14 to P30).

Significantly, our gain-of-function transgenics reproduce the cerebellar phenotype of reduced size and foliation seen in the cyclin D1/D2 null and Math1-overexpressing mouse models (Helms et al., 2001; Ciemerych et al., 2002). However, Math1 overexpression in vivo was not associated with decreased BrdU incorporation (Helms et al., 2001), suggesting that its activity requires coordination with cell cycle arrest, which could be exerted by a $\mathrm{G}_{1}$ checkpoint regulator such as $P C 3$, as we show here (Fig. 9D).

It remains to be verified whether the proposed function of $P C 3$ as a coordinator between cell cycle arrest-exit and differentiation might be more general and applicable to diverse neuronal lineages controlled by different genes that promote neural differentiation, as suggested by the marked prodifferentiative effect of $P C 3$, observed in various CNS and PNS proliferative regions.

\section{References}

Akazawa C, Ishibashi M, Shimizu C, Nakanishi S, Kageyama R (1995) A mammalian helix-loop-helix factor structurally related to the product of Drosophila proneural gene atonal is a positive transcriptional regulator expressed in the developing nervous system. J Biol Chem 270:8730-8738.

Alder J, Cho N, Hatten M (1996) Embryonic precursor cells from the rhombic lip are specified to a cerebellar granule neuron identity. Neuron 17:389-399.

Aruga J, Minowa O, Yaginuma H, Kuno J, Nagai T, Noda T, Mikoshiba K (1998) Mouse Zic1 is involved in cerebellar development. J Neurosci 18:284-293.

Baldin V, Lukas J, Marcote MJ, Pagano M, Draetta G (1993) Cyclin D1 is a nuclear protein required for cell cycle progression in $G_{1}$. Genes Dev 7:812-821.

Belliveau MJ, Cepko CM (1999) Extrinsic and intrinsic factors control the genesis of amacrine and cone cells in the rat retina. Development 126:555-566.

Ben-Arie N, McCall AE, Berkman S, Eichele G, Bellen HJ, Zoghbi HY (1996) Evolutionary conservation of sequence and expression of the bHLH protein Atonal suggests a conserved role in neurogenesis. Hum Mol Genet 5:1207-1216.

Ben-Arie N, Bellen HJ, Armstrong DL, McCall AE, Gordadze PR, Guo Q, Matzuk MM, Zoghbi HY (1997) Math1 is essential for genesis of cerebellar granule neurons. Nature 390:169-172.

Ben-Arie N, Hassan BA, Bermingham NA, Malicki DM, Armstrong D, Matzuk M, Bellen HJ, Zoghbi HY (2000) Functional conservation of atonal and Math1 in the CNS and PNS. Development 127:1039-1048.

Bradbury A, Possenti R, Shooter EM, Tirone F (1991) Molecular cloning of PC3, a putatively secreted protein whose mRNA is induced by nerve growth factor and depolarization. Proc Natl Acad Sci USA 88:3353-3357.

Chomczynski P, Sacchi N (1987) Single-step method of RNA isolation by acid guanidinium thiocyanate-phenol-chloroform extraction. Anal Biochem 162:156-159.

Ciemerych MA, Kenney AM, Sicinska E, Kalaszczynska I, Bronson RT, Rowitch DH, Gardner H, Sicinski P (2002) Development of mice expressing a single D-type cyclin. Genes Dev 16:3277-3289.

Corrente G, Guardavaccaro D, Tirone F (2002) PC3 potentiates NGFinduced differentiation and protects neurons from apoptosis. NeuroReport 13:417-422.

Dahmane N, Ruiz i Altaba A (1999) Sonic hedgehog regulates the growth and patterning of the cerebellum. Development 126:3089-3100.

Eagleson KL, Lillien L, Chan AV, Levitt P (1997) Mechanisms specifying area fate in cortex include cell cycle-dependent decisions and the capacity of progenitors to express phenotype memory. Development 124:1623-1630.

el-Ghissassi F, Valsesia-Wittmann S, Falette N, Duriez C, Walden PD, Puisieux A (2002) BTG2(TIS21/PC3) induces neuronal differentiation and prevents apoptosis of terminally differentiated PC12 cells. Oncogene 21:6772-6778.

Farah MH, Olson JM, Sucic HB, Hume RI, Tapscott SJ, Turner DL (2000) Generation of neurons by transient expression of neural bHLH proteins in mammalian cells. Development 127:693-702.

Fisher M, Trimmer P, Ruthel G (1993) Bergmann glia require continuous association with Purkinje cells for normal phenotype expression. Glia 8:172-182.

Fujita S, Shimada M, Nakamura T (1966) H3-thymidine autoradiographic studies on the cell proliferation and differentiation in the external and the internal granular layers of the mouse cerebellum. J Comp Neurol 128:191-208.

Gavrieli Y, Sherman Y, Ben-Sasson SA (1992) Identification of programmed cell death in situ via specific labeling of nuclear DNA fragmentation. J Cell Biol 119:493-591.

Gazit R, Krizhanovsky V, Ben-Arie N (2004) Math1 controls cerebellar granule cell differentiation by regulating the level of multiple Notch signaling pathway components. Development 131:903-913.

Gossen M, Bujard H (1992) Tight control of gene expression in mammalian cells by tetracycline-responsive promoters. Proc Natl Acad Sci USA 89:5547-5551.

Greene LA (1978) Nerve growth factor prevents the death and stimulates the neuronal differentiation of clonal PC12 pheochromocytoma cells in serum-free medium. J Cell Biol 78:747-755.

Guardavaccaro D, Corrente G, Covone F, Micheli L, D'Agnano I, Starace G, Caruso M, Tirone F (2000) Arrest of $\mathrm{G}_{1}-\mathrm{S}$ progression by the p53inducible gene $\mathrm{PC} 3$ is $\mathrm{Rb}$ dependent and relies on the inhibition of cyclin D1 transcription. Mol Cell Biol 20:1797-1815.

Hatten M (1999) Central nervous system neuronal migration. Annu Rev Neurosci 22:511-539.

Helms AW, Abney AL, Ben-Arie N, Zoghbi HY, Johnson JE (2000) Autoregulation and multiple enhancers control Math1 expression in the developing nervous system. Development 127:1185-1196.

Helms AW, Gowan K, Abney A, Savage T, Johnson JE (2001) Overexpression of MATH1 disrupts the coordination of neural differentiation in cerebellum development. Mol Cell Neurosci 17:671-682.

Hogan B, Costantini F, Lacy E (1995) Manipulating the mouse embryo: a laboratory manual, Sec C and E, Ed 2, pp 127-178, 219-248. Plainview, NY: Cold Spring Harbor.

Iacopetti P, Barsacchi G, Tirone F, Maffei L, Cremisi F (1994) Developmental expression of PC3 gene is correlated with neuronal cell birthday. Mech Dev 47:127-137.

Iacopetti P, Michelini M, Stuckmann I, Oback B, Aaku-Saraste E, Huttner WB (1999) Expression of the antiproliferative gene TIS21 at the onset of neurogenesis identifies single neuroepithelial cells that switch from proliferative to neuron-generating division. Proc Natl Acad Sci USA 96:4639-4644.

Johnson JE, Birren SJ, Anderson DJ (1990) Two rat homologues of Drosophila achaete-scute specifically expressed in neuronal precursors. Nature 346:858-861.

Kauffman SL (1968) Lengthening of the generation cycle during embryonic differentiation of the mouse neural tube. Exp Cell Res 49:420-424.

Kaufman MH (1999) The atlas of mouse development. London: Academic.

Kenney AM, Rowitch DH (2000) Sonic hedgehog promotes $G_{1}$ cyclin expression and sustained cell cycle progression in mammalian neuronal precursors. Mol Cell Biol 20:9055-9067.

Kistner A, Gossen M, Zimmermann F, Jerecic J, Ullmer C, Lubbert H, Bujard H (1996) Doxycycline-mediated quantitative and tissue-specific control of gene expression in transgenic mice. Proc Natl Acad Sci USA 93:10933-10938.

Knoepfler PS, Cheng PF, Eisenman RN (2002) N-myc is essential during neurogenesis for the rapid expansion of progenitor cell populations and the inhibition of neuronal differentiation. Genes Dev 16:2699-2712.

Komuro H, Yacubova E, Yacubova E, Rakic P (2001) Mode and tempo of tangential cell migration in the cerebellar external granular layer. J Neurosci 21:527-540.

Latella L, Sacco A, Pajalunga D, Tiainen M, Macera D, D'Angelo M, Felici A, Sacchi A, Crescenzi M (2001) Reconstitution of cyclin D1-associated 
kinase activity drives terminally differentiated cells into the cell cycle. Mol Cell Biol 21:5631-5643.

Lee JE (1996) Basic helix-loop-helix genes in neural development. Curr Opin Neurobiol 7:13-20.

Levi G, Aloisi F, Ciotti MT, Thangnipon W, Kingsbury A, Balasz R (1989) Preparation of $98 \%$ pure cerebellar granule cell cultures. In: A dissection and tissue culture manual of the nervous system (Shahar A, deVellis J, Vernadakis A, Haber B, eds), pp 211-214. New York: Liss.

Levitt P, Rakic P (1980) Immunoperoxidase localization of glial fibrillary acidic protein in radial glial cells and astrocytes of the developing rhesus monkey brain. J Comp Neurol 193:815-840.

Ma Q, Kintner C, Anderson DJ (1996) Identification of neurogenin, a vertebrate neuronal determination gene. Cell 87:43-52.

Mares V, Lodin Z, Srajer J (1970) The cellular kinetics of the developing mouse cerebellum. I. The generation cycle, growth fraction and rate of proliferation of the external granular layer. Brain Res 23:323-342.

Matsuda S, Rouault J, Magaud J, Berthet C (2001) In search of a function for the TIS21/PC3/BTG1/TOB family. FEBS Lett 497:67-72.

Matsushime H, Roussel MF, Ashmun RA, Sherr CJ (1991) Colonystimulating factor 1 regulates novel cyclins during the G1 phase of the cell cycle. Cell 65:701-713.

McConnell SK, Kaznowski CE (1991) Cell cycle dependence of laminar determination in developing neocortex. Science 254:282-285.

Mitsuhashi T, Aoki Y, Eksioglu YZ, Takahashi T, Bhide PG, Reeves SA, Caviness Jr VS (2001) Overexpression of p27Kip1 lengthens the G1 phase in a mouse model that targets inducible gene expression to central nervous system progenitor cells. Proc Natl Acad Sci USA 98:6435-6440.

Miyata T, Maeda T, Lee JE (1999) NeuroD is required for differentiation of the granule cells in the cerebellum and hippocampus. Genes Dev 13:1647-1652.

Montagnoli A, Guardavaccaro D, Starace G, Tirone F (1996) Overexpression of the nerve growth factor-inducible PC3 immediate early gene is associated to inhibition of cell proliferation. Cell Growth Differ 7:1327-1336.

Morrison ME, Mason CA (1998) Granule neuron regulation of Purkinje cell development, striking a balance between neurotrophin and glutamate signaling. J Neurosci 18:3563-3573.

Oberhammer FA, Pavelka M, Sharma S, Tiefenbacher R, Purchio AF, Bursch W, Schulte-Hermann R (1992) Induction of apoptosis in cultured hepatocytes and in regressing liver by transforming growth factor beta 1 . Proc Natl Acad Sci USA 89:5408-5412.

Ohnuma S, Philpott A, Harris WA (2001) Cell cycle and cell fate in the nervous system. Curr Opin Neurobiol 11:66-73.

Ohnuma S-I, Hopper S, Wang KC, Philpott A, Harris WA (2002) Coordinating retinal histogenesis, early cell cycle exit enhances early cell fate determination in the Xenopus retina. Development 129:2435-2446.
Qin H, Gunning P (1997) The $3^{\prime}$-end of the human $\beta$-actin gene enhances activity of the $\beta$-actin expression vector system, construction of improved vectors. J Biochem Biophys Methods 36:63-72.

Rakic P (1971) Neuron-glia relationship during granule cell migration in developing cerebellar cortex. A golgi and electron microscopy study in Macacus rhesus. J Comp Neurol 141:283-312.

Rouault JP, Prevot D, Berthet C, Birot AM, Billaud M, Magaud JP, Corbo L (1998) Interaction of BTG1 and p53-regulated BTG2 gene products with mCaf1, the murine homolog of a component of the yeast CCR4 transcriptional regulatory complex. J Biol Chem 273:22563-22569.

Shambaugh III GE, Lee RJ, Watanabe G, Erfurth F, Karnezis AN, Koch A, Haines III GK, Halloran M, Brody BA, Pestell RG (1996) Reduced cyclin D1 expression in the cerebella of nutritionally deprived rats correlates with developmental delay and decreased cellular DNA synthesis. J Neuropathol Exp Neurol 55:1009-1020.

Shambaugh III GE, Haines III GK, Koch A, Lee EJ, Zhou J, Pestell R (2000) Immunohistochemical examination of the INK4 and Cip inhibitors in the rat neonatal cerebellum: cellular localization and the impact of protein calorie malnutrition. Brain Res 855:11-22.

Sommer L, Rao M (2002) Neural stem cells and regulation of cell number. Prog Neurobiol 66:1-18.

Sotelo C, Alvarado-Mallart RM, Frain M, Vernet M (1994) Molecular plasticity of adult Bergmann fibers is associated with radial migration of grafted Purkinje cells. J Neurosci 14:124-133.

Tata AM (2001) An in situ hybridization protocol to detect rare mRNA expressed in neural tissue using biotin-labelled oligonucleotide probes. Brain Res Brain Res Protoc 6:178-184.

Tiemann F, Hinds PW (1998) Induction of DNA synthesis and apoptosis by regulated inactivation of a temperature-sensitive retinoblastoma protein. EMBO J 17:1040-1052.

Tirone F (2001) The gene PC3 ${ }^{\mathrm{TIS} 21 / \mathrm{BTG} 2}$, prototype member of the PC3/ BTG/TOB family, regulator in control of cell growth, differentiation, and DNA repair? J Cell Physiol 187:155-165.

Wilkinson DG (1992) Whole mount in situ hybridization of vertebrate embryos. In: In situ hybridization, a practical approach (Wilkinson DG, ed), pp 75-83. Oxford: IRL.

Wingate RJT (2001) The rhombic lip and early cerebellar development. Curr Opin Neurobiol 11:82-88.

Yang XW, Wynder C, Doughty ML, Heintz N (1999) BAC-mediated genedosage analysis reveals a role for Ziprol (Ru49/Zfp38) in progenitor cell proliferation in cerebellum and skin. Nat Genet 22:327-335.

Zecevic N, Rakic P (1976) Differentiation of Purkinje cells and their relationship to other components of developing cerebellar cortex in man. J Comp Neurol 167:27-48. 